\title{
High-resolution flow simulation in Typhoon 21, 2018: massive loss of submerged macrophytes in Lake Biwa
}

\author{
Satoshi Nakada ${ }^{*}$, Hiroki Haga², Maho Iwaki ${ }^{1,2}$, Kohji Mabuchi $^{1}$ and Noriko Takamura
}

\begin{abstract}
The global activities of typhoons and hurricanes are gradually changing, and these storms can drastically affect lake ecosystems through the recession of submerged macrophytes that regulate the water quality in lakes. Using an echosounder, we captured the short-term, massive loss of submerged macrophytes attributed to the abnormal fluctuation of the water level induced by the approach of a catastrophic super typhoon in the southern basin of Lake Biwa, Japan. This paper investigates the physical processes responsible for the loss of vegetation using a highresolution circulation model in Lake Biwa as a pilot study area. The circulation model was coupled with dynamical models of the fluid force and erosion acting on the vegetation. Our simulation successfully reproduced the water level fluctuation and high-speed current (torrent) generated by the typhoon gale. The simulated results demonstrated that the fluid force driven by the gale-induced torrent uprooted submerged macrophytes during the typhoon approach and that this fluid force (rather than erosion) caused the outflow of vegetation. As a result, this uprooting attributed to the fluid force induced the massive loss of submerged macrophytes in a large area of the southern basin, which might have increased primary production and reduced the stock of fish such as bluegill in the lake. Our model can estimate the reduction in the macrophyte height within the range of -1.3 to $-0.4 \mathrm{~m}$, suggesting that fluid forces greater than the time-averaged value $\left(1.24 \times 10^{-4} \mathrm{~N}\right)$ were available. Flow speeds of approximately $0.8 \mathrm{~m} / \mathrm{s}$ might be the critical value that induces the fluid force acting on the uprooting of the submerged macrophytes. Our approach is practical for evaluating changes in lake environments attributed to the massive outflow of submerged macrophytes under various climate change scenarios.
\end{abstract}

Keywords: Flow simulation, Typhoon, Submerged macrophytes, Lake Biwa, Fluid force

\section{Introduction}

The global activities of tropical storms (typhoons and hurricanes), which can drastically affect wetland and lake ecosystems, are gradually changing. Moreover, tropical storms disturb the community structures of aquatic plants in tropical and temperate regions (Wang et al. 2016). For example, hurricanes Katrina and Rita eroded the freshwater marshes of the Louisiana coastal wetlands in 2005 and caused significant uprooting (Howes et al.,

\footnotetext{
* Correspondence: nakada.satoshi@nies.go.jp

${ }^{1}$ National Institute for Environmental Studies, 16-2 Onogawa, Tsukuba, Ibaraki 305-8506, Japan

Full list of author information is available at the end of the article
}

2010). Many lakes in these regions are within the strike zones of tropical storms, and they experience high interseasonal and interannual variations in rainfall and runoff (Havens et al. 2016a). Havens et al. (2016a) reported the case of Lake Okeechobee and found that three hurricanes significantly reduced the coverage of submerged aquatic vegetation to one-tenth and affected water quality and plankton dynamics in open water zones. Terrestrial loadings in periods of high rainfall could enhance dissolved color, reduce irradiance, increase water turnover rates that suppress blooms, and markedly alter the ecosystems in lakes located in regions where oceanic cycles and their teleconnections result in decadal variation 
in rainfall (Havens et al. 2016b). With model results predicting future warming of the tropical sea surface, the Intergovernmental Panel on Climate Change (IPCC 2007) reported that tropical cyclones will become more intense, leading to more violent winds and rainfall.

Aquatic plants, particularly submerged macrophytes, play an important role in aquatic environments by positively interacting with the water quality and ecosystems of lakes. The submerged macrophytes in shallow eutrophic lakes can affect nutrient cycling, sediment-water interactions, water column irradiance, and phytoplankton blooms (Weisner et al. 1997). The vegetation of submerged macrophytes supplies a variety of ecosystem functions, providing shelters for fish and aquatic invertebrates, restoring water quality, and regulating the oxygen balance (Sood et al. 2012). Accordingly, recent studies have focused on the phytoremediation and purification effects of submerged macrophytes on nutrient-polluted water (e.g., Sood et al. 2012; Yanran et al. 2012; Dhote and Dixit, 2009), implying that coverage reductions of aquatic plants could negatively affect the water quality in shallow lakes. To understand water quality fluctuations, the physical processes of the vegetation coverage changes should be clarified; therefore, this study focuses on the processes in the short-term period that are as yet unexplained.

The ecosystem in a shallow lake can change drastically during the short-term approach of a storm coincident with the recession of aquatic plants. Ji et al. (2018) reported that a lake disturbed by tropical storms experienced a regime shift from clear to turbid water due to losing submerged vegetation. Heavy rainfall, flooding, and strong winds can also create suitable habitats for aquatic organisms and increase their diversity in regions frequently affected by typhoons (Wang et al. 2008).

To understand the short-term changes taking place within a lake ecosystem, we need to know the physical processes that induce the large-scale recession of aquatic plants; unfortunately, no analysis has been performed to reinforce this knowledge. Damage to aquatic plants varies based on the life forms of the species, geological habitat conditions, and tropical storm intensity (Wang et al. 2016). For example, tropical storms cause damage to mangroves, including the loss of foliage, breakage of trunks, and even uprooting of trees (Ellison 1998). Heavy storms have induced a shift to a permanent turbid state by destroying vegetation (McKinnon and Mitchell 1994). The most important potential impact of storms can be through their effect on water level fluctuations (Scheffer and van Nes 2007). However, little is known about the process by which submerged macrophytes disappear during tropical storms. The issue of the recession processes of vegetation related to water level fluctuations is clearly far from resolved at short time scales, such as storm periods. This lack of knowledge exists because no biological data that would be useful for analyzing the disappearance of submerged macrophytes are available both before and after a typhoon strike.

As a consequence, a simulation coupled with flow and dynamical models on high-resolution grids is needed to analyze the dissipation of submerged macrophytes; in addition, observational data are needed to describe the loss of vegetation. The use of a high-resolution flow model can be a powerful approach for simulating the massive loss of submerged macrophytes. To date, various models have been proposed for simulating lake circulation (e.g., Akitomo et al. 2009), water temperature and the thermocline (e.g., Koue et al. 2018), dissolved oxygen (Kitazawa et al. 2010), primary production (Sato et al. 2011), and other features at seasonal and interannual time scales; nevertheless, the grid resolutions of these models are insufficient for representing the detailed flow field with a focus on submerged macrophytes. In this context, previous studies have proposed a theoretical framework and bulk models for the fluid force acting on submerged macrophytes (e.g., Luhar and Nepf 2011; Hayashi and Konno 2007). Fortunately, we succeeded in collecting the observational plant height data that are necessary for capturing the massive loss of submerged macrophytes by conducting echosounder surveying on a regular schedule.

This paper investigates the short-term, massive loss of submerged macrophytes as a result of the approach of a catastrophic super typhoon in Lake Biwa, Japan, which is taken as a pilot study area (Fig. 1). To investigate the processes that caused the outflow of vegetation, we assume that the outflow can be attributed to the uprooting of submerged macrophytes induced by the erosion of the bed and fluid force acting on the vegetation body. Therefore, we proposed two dynamical models, namely, erosion and fluid force models, focusing on the habitats of the submerged macrophytes in the lake. In the first model, the outflow can be induced by erosion generated by a strong current or torrent (Fig. 2a). In the second model, the outflow can be induced by the fluid force generated by the torrent (Fig. 2b). Then, a numerical fluid simulation was coupled with an evaluation of the fluid force and erosion models to identify the key physical factors governing this massive loss. The erosion and fluid force may be influenced by wind waves and river runoff, which will be discussed in Section 4.

\section{Study area}

Lake Biwa (Fig. 1) is the largest lake in Japan (with a volume of $27.5 \mathrm{~km}^{3}$ ), providing water resources for approximately 14.5 million people in the Kansai region (e.g., the Shiga, Kyoto, Osaka, and Hyogo regions), including some megacities. The lake, which has a surface area of 


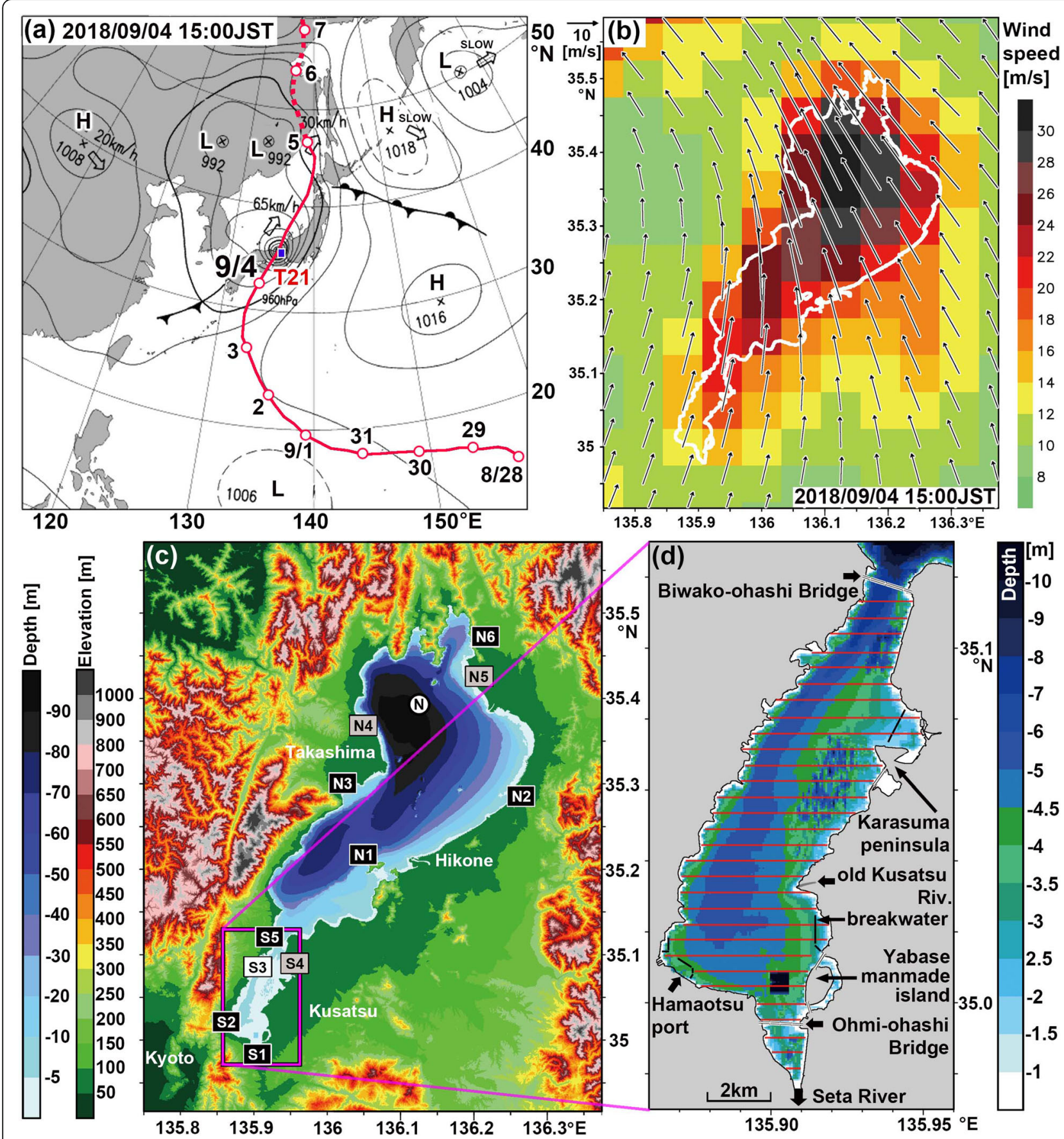

Fig. 1 Maps of the a pressure distribution when Typhoon 21 approached Lake Biwa and the typhoon course (red line and dots), with the blue square indicating the area around Lake Biwa shown in Fig. 1b, b wind vectors and speeds (colors) based on the GPV-MSM reanalysis dataset at 15:00 on 4 September, and c topography and bathymetry around and in Lake Biwa, respectively. The black and gray squares indicate the gauge stations operated by the Ministry of Land, Infrastructure, Transport and Tourism of Japan (MLIT) and the Lake Biwa Branch Office of the National Institute for Environmental Studies (LaBBO-NIES), respectively. White squares denote the Ogoto offshore comprehensive automatic observation station (OOCAOS) in the southern basin of Lake Biwa. $\mathbf{d}$ Bathymetric maps for the analysis in the southern basin. The black solid lines indicate the transect lines for the echosounding observations to measure the vegetation height of the submerged macrophytes

$670 \mathrm{~km}^{2}$, is located on the central island of the Japanese archipelago, Honshu. Lake Biwa consists of two basins, a deep northern basin (area-mean depth of $44 \mathrm{~m}$, maximum depth of 104 $\mathrm{m}$ ) and a shallow southern basin (area-mean depth of $4 \mathrm{~m}$ ); the latter, which represents our study field, has a surface area of $51.6 \mathrm{~km}^{2}$ (Haga 


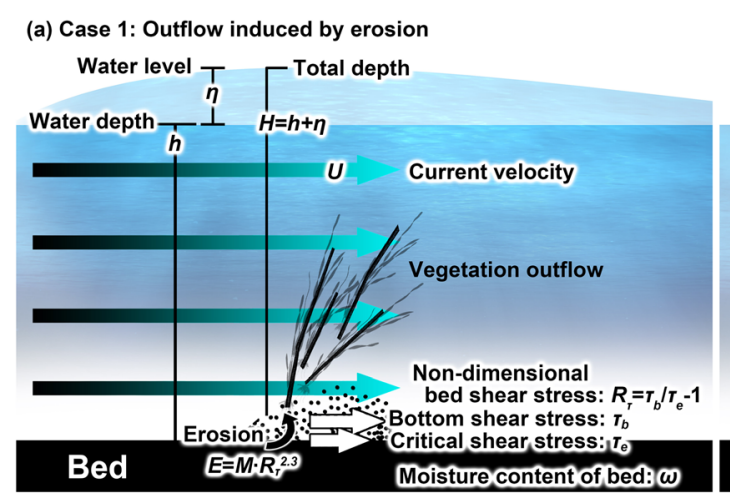

(b) Case 2: Outflow induced by fluid force

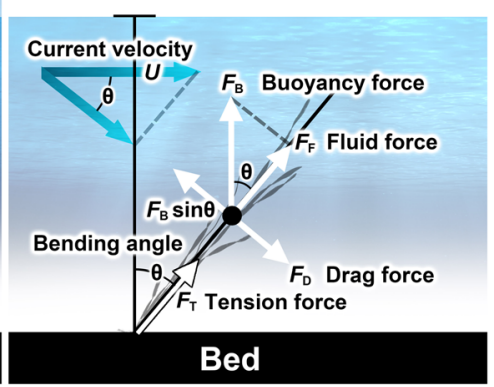

Fig. 2 Conceptual diagrams of the two processes responsible for the vegetation outflow induced by the high-speed current. a Erosion (case 1) evaluated by the nondimensional bed shear stress and the sediment flux from the bed to the lake water. $\mathbf{b}$ Fluid force (case 2) represented by the resultant of the buoyancy and drag forces. The variables depicted in the diagram are explained further in the text

2006). The lake water is generally provided by more than 100 rivers in the watershed $\left(3174 \mathrm{~km}^{2}\right)$ and is discharged through a single outlet (Kawanabe et al. 2012), namely, the Seta River in the south, under the control of a weir that regulates the runoff and water level of the lake. In recent years, extensive beds of submerged macrophytes have developed in the southern basin. Over the last two decades, submerged macrophytes covered over $90 \%$ of the area of the southern basin (Haga and Ishikawa 2016).

\section{Methods and data}

\subsection{Model}

We evaluated the key factors of the above processes by following the procedure of the flow chart shown in Fig. 3 ; we coupled a circulation model with two dynamical models to represent the outflow of submerged

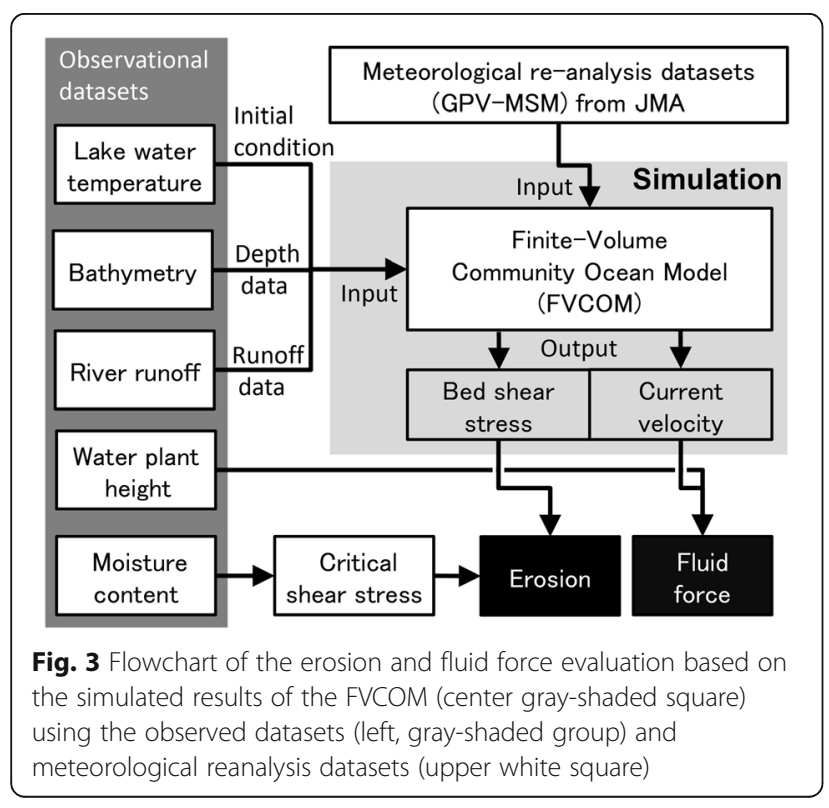

macrophytes described in Section 2. We simulated the large-scale changes in the lake water level induced by Typhoon 21 using an unstructured-grid ocean model and atmospheric reanalysis data. Then, the shear stress and fluid force acting on flexible plants were calculated based on bed shear stress theory and a hydraulic resistance model, respectively. The bed shear stress theory used for the erosion model is later described in Subsection 3.1.3, the fluid force model is explained in Subsection 3.1.4, and the model's input datasets are summarized in Table 1.

\subsubsection{Lake circulation model}

In the simulation part of the flowchart (Fig. 3), we used the prognostic, unstructured-grid, finite-volume community ocean model (FVCOM) (Chen et al. 2003). This finite-volume approach ensures the conservation of mass and heat necessary to reproduce the key physical processes under a dominant change in the water level of the lake. The FVCOM uses an unstructured, terrain-following triangular grid, leading to improved flexibility in adjusting the grid resolution $(10-60 \mathrm{~m})$ to fit the irregular coastal geometry and bathymetry of Lake Biwa (Fig. 4). A $\sigma$-z mixed coordinate system consisting of five constant-thickness $(0.5$ $\mathrm{m})$ layers in the surface layer and a 10-sigma layer below the surface was employed in the vertical dimension to represent realistic temperature stratification (Nakada et al. 2017).

Considering the observed large fluctuation in the water level induced by Typhoon 21 (explained in detail in Section 4.2), the simulation was conducted for a week following the approach of Typhoon 21 to the lake on 4 September 2018. The ocean simulations with a time interval of $0.2 \mathrm{~s}$ began from an initial state of rest and lasted for 2 weeks with a start date of 29 August 2018. 
Table 1 The list of specifications for the datasets used in the simulation and analysis

\begin{tabular}{|c|c|c|c|c|c|c|}
\hline Dataset & Usage & $\begin{array}{l}\text { Data } \\
\text { source }\end{array}$ & Category & $\begin{array}{l}\text { Time } \\
\text { interval }\end{array}$ & Data period & $\begin{array}{l}\text { Observational } \\
\text { location }\end{array}$ \\
\hline $\begin{array}{l}\text { Lake water } \\
\text { temperature }\end{array}$ & Initial condition of simulation & LBERI & Observation & Monthly & 28 Aug., 2018 & Fig.1c \\
\hline Bathymetry & Initial condition of simulation & LBERI & Observation & \multicolumn{2}{|c|}{ Compiration of the various dataset } & Fig.1c \\
\hline Water plant height & $\begin{array}{l}\text { Input for fluid force } \\
\text { calculation }\end{array}$ & LBM & Observation & Monthly & $\begin{array}{l}9 \text { Aug. \& } 5 \text { Sep., } \\
2018\end{array}$ & Fig.1d \\
\hline Moisture content & Input for erosion calculation & LBM & Observation & snapthot & 9-11 Sep, 2002 & Fig.5 \\
\hline Meteorological data & Input for simulation & JMA & Re-analysis & hourly & 29-12 Sep., 2018 & Fig.1b \\
\hline River runoff & Input for simulation & MLIT & Estimation & hourly & 2-5 Sep., 2018 & Fig.1a \\
\hline Water level & Validation for simulation & MLIT\&NIES & Observation & hourly & 2-5 Sep., 2018 & Fig.1c \\
\hline Wind speed & Validation for simulation & JWA & Observation & hourly & 2-6 Sep., 2018 & Fig.1c \\
\hline Chlorophyll-a & Data analysis & JWA & Observation & hourly & 2-5 Sep., 2018 & Fig.1c \\
\hline
\end{tabular}

\subsubsection{Input data to the circulation model}

Four input datasets, namely, bathymetry, water temperature, runoff, and meteorological reanalysis datasets, were used in the simulation, as shown in the flowchart (Fig. 3) and summarized in Table 1. We used bathymetry data with a $50 \mathrm{~m}$ horizontal resolution (Fig. $1 \mathrm{c}$ and d) distributed by the Lake Biwa Environmental Research Institute (LBERI) of Shiga Prefecture as the input data to the simulation and interpolated these data to the unstructured grids in the FVCOM (Fig. 4). The in situ temperature data observed on 28 August at Imaduoki-Chuou (Fig. 1c) obtained by LBERI were used as the initial water temperature conditions in the simulation and were homogeneously input to our model horizontally.

The hourly mean river discharges from the Seta River used in the simulation (Fig. 1d) were observed at the Seta River Weir operated by the Ministry of Land, Infrastructure, Transport and Tourism (MLIT) of Japan, Kinki Regional Development Bureau Biwako Office. We considered the river runoff from five major watershed areas and observed outflow runoff from the Seta River in the simulation (Fig. 4a). The daily mean river discharges were estimated from the precipitation, observed water levels around Lake Biwa, and outflow runoff from the Seta River and were linearly interpolated as the hourly input data (Fig. 7).

Reanalysis meteorological Grid Point Value datasets of the Meso-Scale Model (GPV-MSM) produced by the Japan Meteorological Agency (JMA) were downloaded from the server of the Research Institute for the Sustainable Humanosphere (http://database.rish.kyoto-u.ac.jp/ arch/jmadata/) and input into the FVCOM as the mean hourly meteorological data including air pressure at the land surface, air temperature at $2 \mathrm{~m}$, precipitation, cloud cover, relative humidity, and wind velocity at $10 \mathrm{~m}$. Each meteorological datapoint $m_{i}$ was inter/extrapolated to each computational grid as the averaged value, $m_{i}=\Sigma$
$m_{G P V} w / \sum w$ (Nakada and Isoda 2000), where $m_{G P V}$ is from the GPV-MSM datasets, and $w$ is a Gaussian weight function defined by $w=\exp \left(D^{2} / r_{G}{ }^{2}\right)$. Here, $D$ is the distance between the data and computational grid point, and $r_{G}(=20 \mathrm{~km})$ is the e-folding horizontal scale (influence of the Gaussian radius), which is nearly equal to four times the mesh size of GPV-MSM $(\sim 5 \mathrm{~km})$.

\subsubsection{Erosion estimation}

The erosion induced by bed flow can excavate the sediment on the lake bottom, leading to the uprooting of submerged macrophytes. A conceptual model (Fig. 2a) exhibiting the concepts underlying the calculation of the nondimensional bed shear stress, sediment resuspension, and the flux of sediment from the lakebed to the lake water was employed in similar simulations (e.g., Nakada et al. 2018). The nondimensional bed shear stress, $R_{\tau}$, at each computational grid was obtained from the following equations (Umita et al. 1988):

$$
\begin{aligned}
& R_{\tau}=\tau_{b} / \tau_{e}-1 \\
& \tau_{b}=\rho_{w} u^{2} \\
& \tau_{e}=0.79 \tau_{y}^{0.94}
\end{aligned}
$$

where $\tau_{b}$ is the bed shear stress, and $\tau_{e}$ is the critical shear stress based on the empirical formula (Otsubo and Muraoka 1985). When $\tau_{b}>\tau_{e}$, or in other words, $R_{\tau}>0$, bed sediment can be transported from the seabed into the lake water. Here, $\rho_{w}\left(1000 \mathrm{~kg} \mathrm{~m}^{-3}\right)$ is the density of lake water, and $u=\sqrt{g n^{2} U^{2} / D^{1 / 3}}$ is the bottom friction velocity, which is determined by the gravitational acceleration constant $g\left(9.8 \mathrm{~m} \mathrm{~s}^{-2}\right)$, the roughness coefficient $n$ (0.025), the current speed $U$, and the total depth $D$ (= $h+H)$. Here, $h$ is the water depth, and $H$ is the water level. $\tau_{y}=1.494 \times 10^{6} \omega^{-2.452}$ is the yield value (Nakano et al. 1991), which is determined by the moisture ratio 

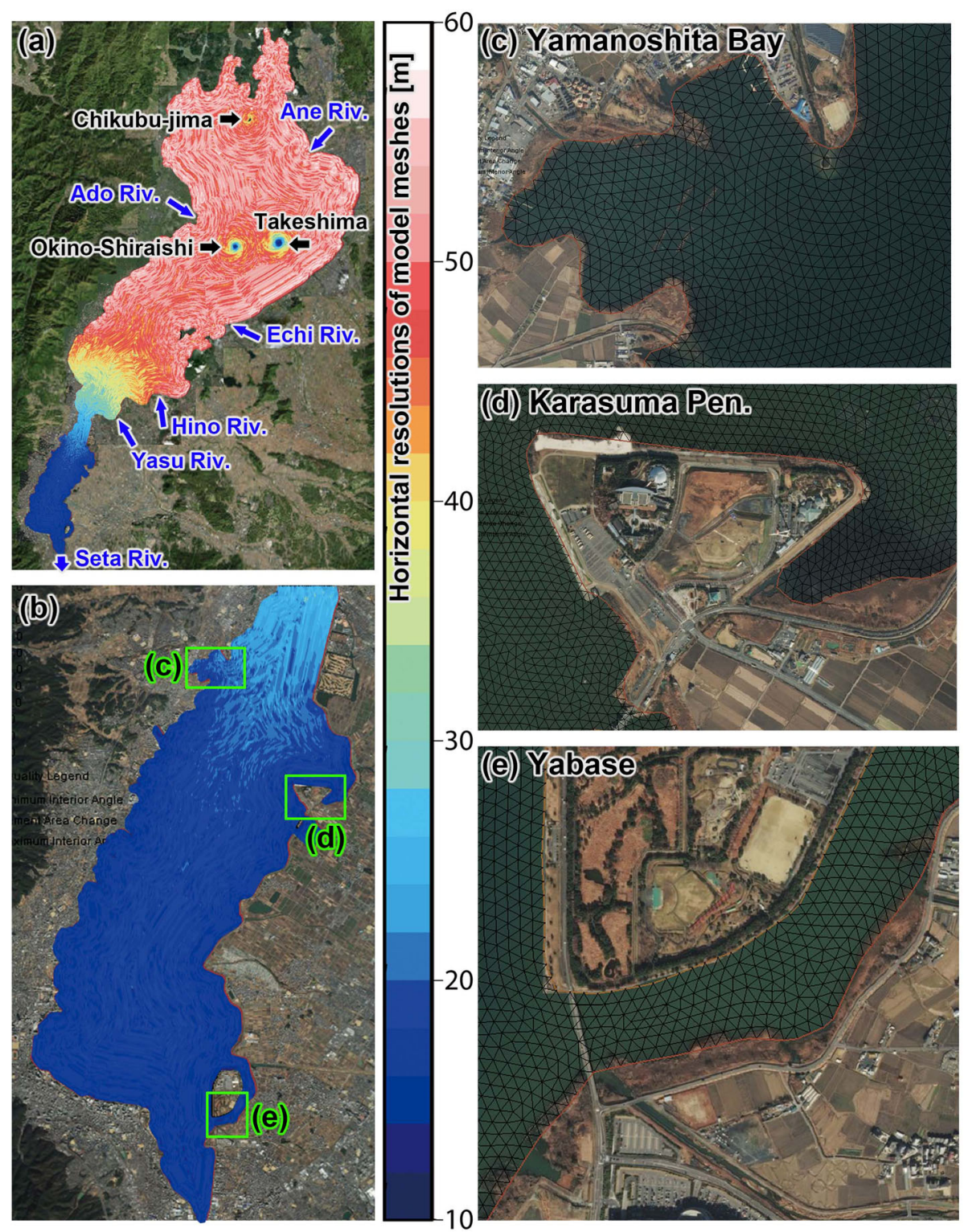

Fig. 4 Maps of the unstructured triangular grids in the FVCOM for a the whole basin of Lake Biwa and (b) the southern basin. The total numbers of triangular cells and nodes are 284,569 and 144,037, respectively. The colors indicate that the horizontal resolution of the grids (measured by the side length of each triangle) is 10-60 $\mathrm{m}$ and increases up to 10-20 $\mathrm{m}$ in the southern basin, for example, in c Yamanoshita Bay, $\mathbf{d}$ the Karasuma Peninsula, e the Yabase region, and three small islands in the northern basin

of the bed sediment $\omega=W /(1-W)$ or the moisture content $W$ (Fig. 5). Values of $W$ were produced by inter/extrapolation to the computational grid using a Gaussian function based on sediment observations by the Lake Biwa Museum in 2002 (Haga et al. 2006). The southern basin has a maximum $W$ of $81 \%$ and higher $W$ values than the areas around the Karasuma Peninsula (Fig. 1c) and the entrance of the Seta River $(W<60 \%)$. The instantaneous erosion (or resuspended sediment flux) from the bed $E(t)\left(\mathrm{kg} \mathrm{m}^{-2} \mathrm{~s}^{-1}\right)$ of each grid in the model domain of the southern basin (Fig. 4b) was calculated using the following empirical equation (see Umita et al. 1988; Nakano et al. 1991; Otsubo and Muraoka 1985 for the physical parameters used in the equation):

$$
E(t)=M R_{\tau}^{2.3}
$$

where $M\left(=1.6 \times 10^{-5}\right)$ is the resuspension constant $(\mathrm{kg}$ $\mathrm{m}^{-2} \mathrm{~s}^{-1}$ ), and $t$ is an arbitrary time in the model. The total erosion induced by bed flow is calculated as follows: 


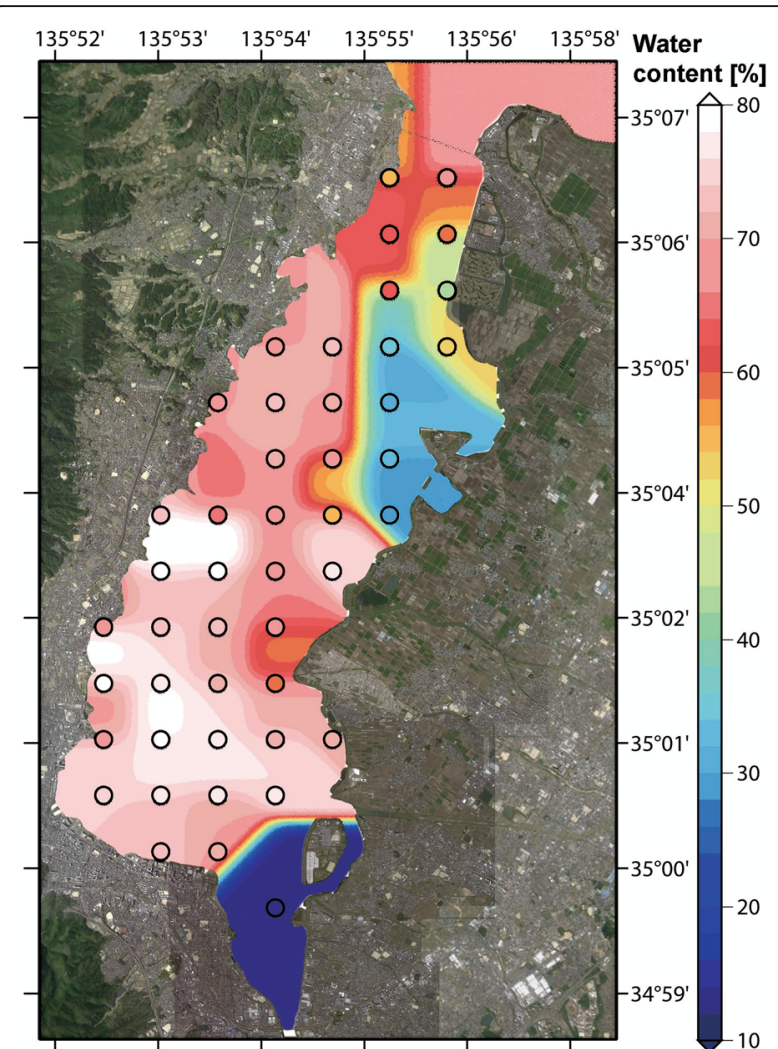

Fig. 5 Map of the moisture content (\%) of the lakebed of the southern basin. Colored dots indicate the observational site moisture contents observed in September 2002 (Haga et al. 2006)

$$
E_{T}=\int_{t_{s}}^{t_{e}} E(t) d t
$$

Regardless of the presence of the submerged macrophytes, the erosion model assumes a plain lakebed characterized only by the water content. In fact, submerged macrophytes suppress the speed of bed flow and lead to damping erosion, which is not represented in this model. Therefore, the erosion model used in the present analysis can have the most dominant effect on the lakebed.

\subsubsection{Fluid force acting on submerged macrophytes}

The fluid force acting on the blades of the submerged macrophytes can be equivalent to the tension force acting on the root of the submerged macrophytes with a bending angle at the lake bottom (Fig. 2b). If the tension force exceeds the critical value of the force with which the lakebed supports the aquatic plants, the plants are uprooted. To evaluate the fluid force, we employed the general theoretical model for buoyant, flexible macrophyte blades in flow (Fig. 2b) (e.g., Luhar and Nepf 2011). In this paper, we employed a few simplifying assumptions without the flow-induced reconfiguration of buoyant, flexible vegetation to evaluate the outflow of submerged macrophytes (Hayashi and Konno 2007). (1) The blades of the submerged macrophytes, such as Vallisneria, were modeled as isolated, buoyant, inextensible elastic stems with a constant representative width $(b=$ $0.01 \mathrm{~m})$, thickness $\left(t_{b}=0.001 \mathrm{~m}\right)$, and density $\left(\rho_{v}=160\right.$

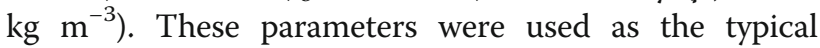
macrophyte model in the experiments of Hayashi and Konno (2007). (2) The horizontal velocity $(U)$ was uniform over depth and had a steady flow on each computational grid with fine scales $(\sim 10 \mathrm{~m})$; the dominant hydrodynamic force was form drag, and unsteady flows, such as those induced by surface waves, were not considered. (3) Viscous skin friction was negligible. Form drag, which is derived from the velocity normal to the blade surface, was represented using a standard quadratic law. The drag force acting on a blade length equivalent to the plant height $h_{v}$ is:

$$
F_{D}=\frac{1}{2} \rho_{w} C_{D} b h_{v} U^{2} \cos ^{2} \theta
$$

Here, $\rho_{w}\left(1000 \mathrm{~kg} \mathrm{~m}^{-3}\right)$ is the density of lake water, and $C_{D}(1.7)$ is the drag coefficient (Hayashi and Konno 2007). The blade length is given by the observed macrophyte height shown in Section 4.1. Hayashi and Konno (2007) evaluated the local bending angle $\theta$ (Fig. 2b) of the blade relative to the vertical $\left(0^{\circ} \leq \theta \leq 90^{\circ}\right.$, where $\theta=$ $0^{\circ}$ denotes an upright posture) based on laboratory experiments. Following their blade model based on the force balance, as shown in Fig. $5 \mathrm{~b}$, the drag force is:

$$
F_{D}=F_{B} \sin \theta
$$

Here, the vertical buoyancy force is:

$$
F_{B}=\left(\rho_{w}-\rho_{v}\right) g t_{b} b h_{v}
$$

and $g\left(9.8 \mathrm{~m} \mathrm{~s}^{-2}\right)$ is the gravitational acceleration constant. The fluid force acting on the blade induced by the flow and buoyancy is:

$$
F_{F}=F_{B} \cos \theta
$$

From Eqs. (6) and (7):

$$
F_{B} \sin \theta=\frac{1}{2} \rho_{w} C_{D} b h_{v} U^{2} \cos ^{2} \theta
$$

Solving Eq. (10), we can obtain the following solution:

$$
\begin{aligned}
& \sin \theta=\left(-F_{B}+\sqrt{F_{B}^{2}+\psi^{2}}\right) / \psi \\
& \cos \theta=F_{B} \sqrt{2\left(\sqrt{1+\left(F_{B} / \psi\right)^{2}}-1\right)} / \psi
\end{aligned}
$$

Here, $\psi=\rho_{w} C_{D} b h_{\nu} U^{2}$. Therefore, the fluid force can be derived using the simulated current velocity $U$ and the observed macrophyte height $h_{v}$ : 


$$
F_{F}=F_{B}^{2} \sqrt{2\left(\sqrt{1+\left(F_{B} / \psi\right)^{2}}-1\right)} / \psi
$$

In this fashion, we calculated the fluid force $F_{F}$ at each model time step and evaluated the outflow of the submerged macrophytes from the bed.

\subsection{Data}

\subsubsection{Plant height data}

We used the plant height data of submerged macrophytes derived by echosounding surveys conducted on a regular schedule by Lake Biwa Museum (LBM) in the pretyphoon period (on 9 and 10 August 2018) and in the posttyphoon period (on 5, 6, and 12 September). The observation configuration was composed of a BioSonics MX Echosounder system (BioSonics Inc.), which was used to measure the plant heights, and a differential-GPS (d-GPS) WU800 device (Japan Radio, Co., Ltd., Tokyo, Japan) for positioning. The transducer of the echosounder was installed in the bottom of a vessel hull and positioned $0.3 \mathrm{~m}$ underwater. The echosounding surveys, which were capable of covering the vegetation distribution in the southern basin, were conducted along 30 longitudinal transects spaced at intervals of $500 \mathrm{~m}$ at a vessel speed of $9-13 \mathrm{~km} / \mathrm{h}$ (5-7 knots), as shown in Fig. 1d.

The raw data derived by the echosounder were processed by Visual Habitat (BioSonics Inc.) to detect the lake bottom and submerged macrophytes based on the default detection configuration, although we manually modified the configuration as appropriate. The detection limit for plant heights was set to $0.1 \mathrm{~m}$. The processed data, formatted as comma-separated values (CSV), were interpolated by inter/extrapolation into the triangular grids of the FVCOM (Fig. 4) using a Gaussian function (Nakada and Isoda 2000). The grid datasets were used to calculate the difference in the plant heights between the pre- and posttyphoon periods and to estimate the fluid force acting on the macrophytes using the plant height $h_{v}$ based on Eqs. (6-9).

\subsubsection{Water level and chlorophyll-a data}

Figure 1c shows the observation stations operated by the MLIT, the Japan Water Agency (JWA), and the Lake Biwa Branch Office of the National Institute for Environmental Studies. In situ water level data were used to verify the simulated water level to ensure the reproducibility of the model. The MLIT releases realtime, observational data on the water level at gauge stations. The water level data were downloaded from the website of the Water Information System run by the MLIT (http://www1.river.go.jp/), with an analysis period corresponding to the span of the simulated data to allow a comparison of the in situ data with the simulated water level data. We used meteorological data, such as wind, water level, and chlorophyll-a, and water quality data observed at the Ogoto offshore comprehensive automatic observation station operated by the JWA. Due to the potential for the biofouling of in-water instrumentation, the sensors were maintained by the JWA at regular semimonthly intervals. We also collected hourly water level data at three stations (Fig. 1c) using HOBO U20L-02 water level loggers (Onset Computer Corporation, USA).

\section{Results}

\subsection{Massive loss of submerged macrophytes}

Figure 6 displays the observed height of the submerged macrophytes on 9 August 2018, as measured by the onboard echosounder, which indicates that there was a substantial area of submerged macrophytes in the southern basin. The submerged macrophyte beds $\left(36.4 \mathrm{~km}^{2}\right)$ covered $68 \%$ of the area of the southern basin, and the area-mean height was $0.54 \mathrm{~m}$.

The approach of Typhoon 21 might have induced the large-volume outflow of submerged macrophytes and short-term blooms of phytoplankton over a large area of the southern basin. On 4 September 2018, category 5 super Typhoon 21 (Jebi) approached Lake Biwa at 15:00 JST (Fig. 1a) and induced a south-tosoutheast gale in the surface layer (Fig. 1b). After the typhoon's approach, the submerged macrophyte height on 5 September significantly decreased throughout the whole basin (area-mean height 0.23 $\mathrm{m})$, with a $58 \%$ height reduction compared to the area-mean height before Typhoon 21; in particular, the vegetation height was nearly zero in the southern area of the basin. A map of the difference in macrophyte height (Fig. 6c) shows an average decrease in the submerged macrophyte height $(0.31 \mathrm{~m})$ and a reduction in the coverage area of $18.8 \mathrm{~km}^{2}$, which constituted $53 \%$ of the southern basin. The area in which the height decreased accounted for $35.2 \mathrm{~km}^{2}$, which was $97 \%$ of the area of the inherent habitat of the submerged macrophytes. Furthermore, significant decreases in height occurred in three areas: the northcentral area of the basin, the nearshore area along the eastern coast, and the estuarine area around the old Kusatsu River. After the reduction in the area of submerged macrophytes, on 5 September, the concentration of chlorophyll-a in the southern basin nearly doubled relative to the concentration during the pretyphoon period between 1 and 3 September (Fig. 7), although the peaks on 4 September might imply benthic algal resuspension. 

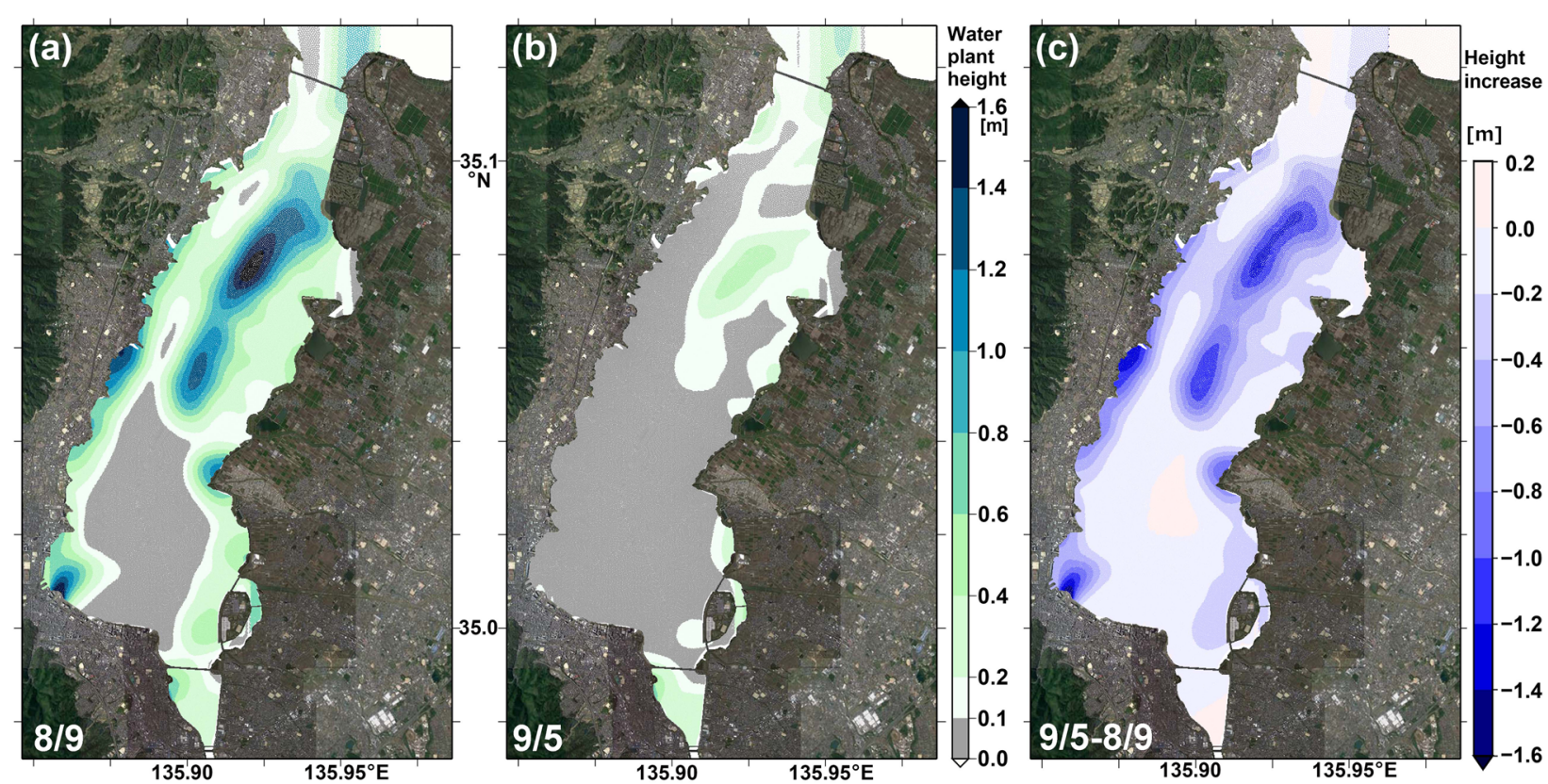

Fig. 6 Distribution of the macrophyte height $(\mathrm{m})$ in the southern basin of Lake Biwa on 9 August 2018 (a) and on 5 September (b). c Temporal change in the macrophyte height derived by subtracting the height on 5 September (b) from the height on 9 August (a)

\subsection{Model validation}

\subsubsection{Wind data used in the simulation}

Figure 8a shows the time series of the area-averaged wind vector over the model domain of the southern basin of Lake Biwa. A southeasterly wind was dominant at noon on 3 September; this condition changed from a strong southerly wind to a southwesterly wind when the typhoon approached Lake Biwa. A map of the wind speeds and vectors is illustrated in Fig. 8b at 15:00 JST on 4. September (red line in Fig. 8a); when Typhoon 21

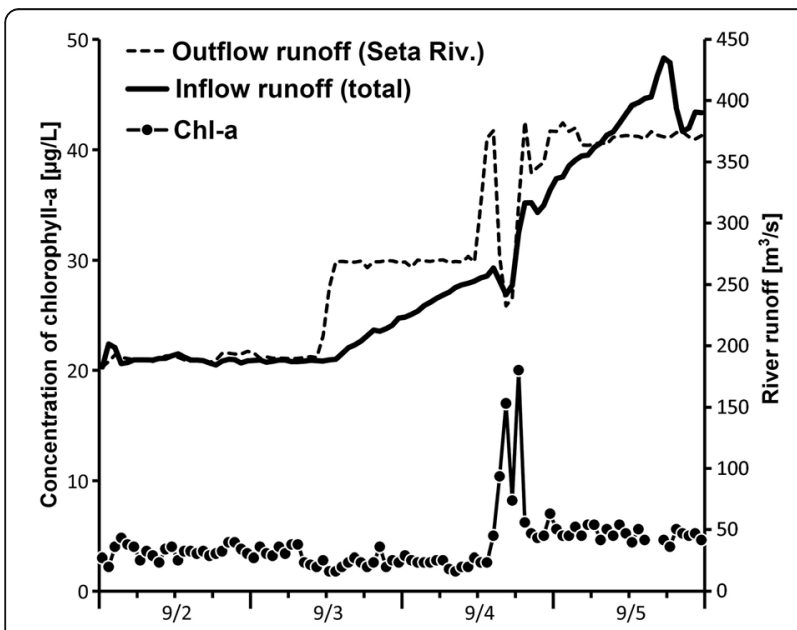

Fig. 7 Temporal variations in the total river runoff into/from Lake Biwa and the chlorophyll-a concentration observed at the OOCAOS located in the southern basin during the period of 2-5 September. The outflow was observed in the Seta River was approaching, Lake Biwa was characterized by a strong southerly wind with a homogeneous horizontal distribution over the lake. The wind speed increased northward and exceeded $28 \mathrm{~m} / \mathrm{s}$ in the northern area of the southern basin.

Figure 8c shows a scatter plot between the GPVMSM-predicted wind speed and the in situ wind speed observed at the Ogoto offshore observation station (Fig. 1c) during the period of 3-6 September, although some data are missing at 15:00 and 16:00 JST on 4 September. The comparison between the observed and predicted wind speeds in this scatterplot suggests that the observed speed was approximately 2 times greater than the predicted speed, leading to the derivation of a wind estimation formula (modified wind $W_{\text {mod }}=1.89 W_{M S M}$ ) from the predicted wind $W_{M S M}$ with a high correlation coefficient $(\mathrm{R}=0.92)$. Following the derived formula, we modified the wind speed input into the simulation.

\subsubsection{Water level fluctuation}

Figure 9a shows the time series of the observed and simulated water levels during the typhoon approach period on 4 September. Both time series at the southern observational site (S2: Mihogasaki) indicate that the predominant decreases (approximately $1 \mathrm{~m}$ ) in the water level at S2 were induced by typhoon winds. On the other hand, the water levels of both time series at the northern observational site (N3: Katayama) increased by approximately $20 \mathrm{~cm}$ when the water level at the southern site was at a local minimum. The increases at N3 and 

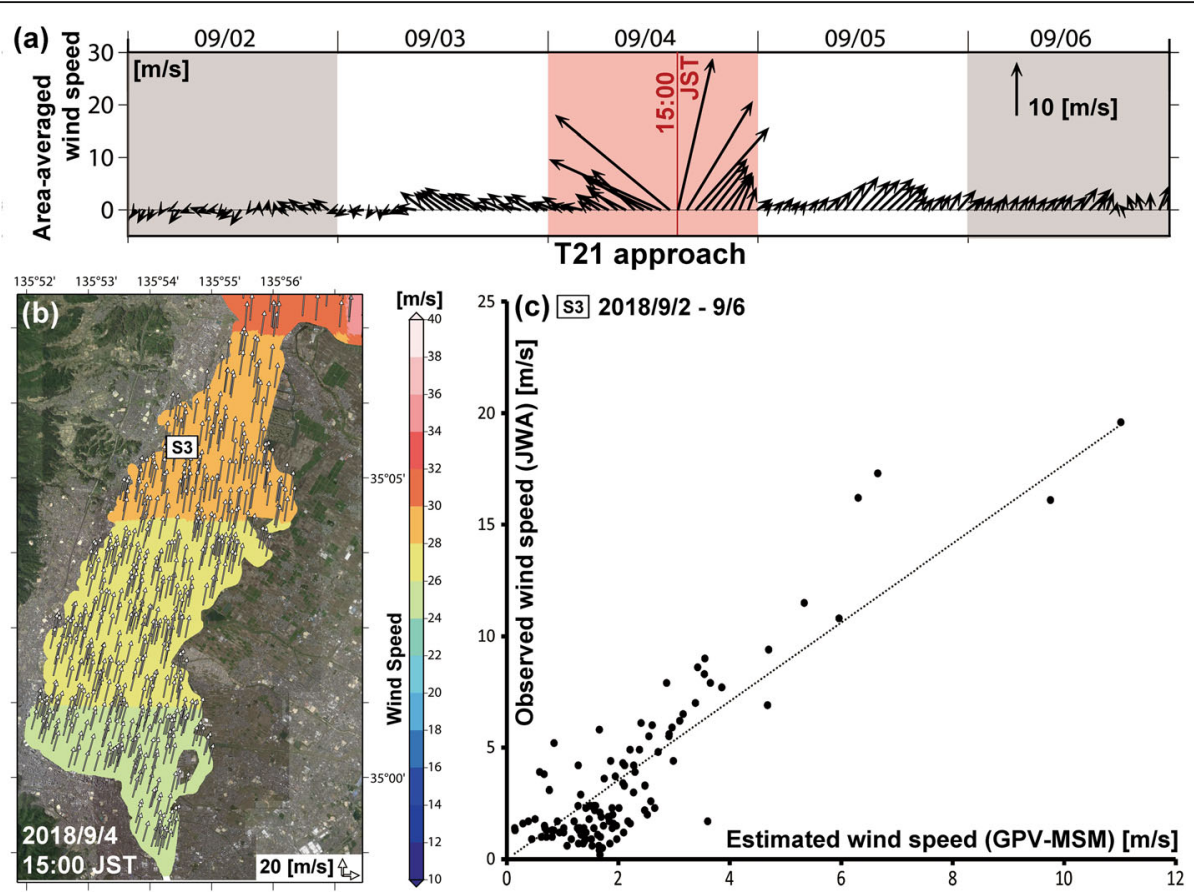

Fig. 8 a Vectors of the area-averaged wind speed derived from the hourly GPV-MSM reanalysis dataset in the southern basin during the period of 2-6 September 2018. Red shading indicates the date of the Typhoon 21 approach around Lake Biwa. $\mathbf{b}$ Map of the wind vectors and speeds (colors) interpolated using the GPV-MSM reanalysis dataset at 15:00 JST on 4 September. c Scatter plots showing the observed and estimated wind speeds during the period of 2-6 September

decreases at S2 started at 14:00 when the wind changed from the southeasterly wind (Fig. 8) to the southsouthwesterly gale $(\sim 30 \mathrm{~m} / \mathrm{s})$ corresponding to the long axis direction of the southern basin (Fig. 1). This explains why the predominant decrease at S2 and higher peak at N3 were induced by the gale.

A comparison between the observed and simulated water levels at all observational sites (Fig. 9b) results in a high correlation coefficient $(\mathrm{R}=0.94, \mathrm{~N}=246)$ and a low calculation error $(\mathrm{RMSE}=12.15 \mathrm{~cm}, \mathrm{BIAS}=-5.35$ $\mathrm{cm})$ compared to the magnitude of the water level change. This suggests that the calculated water levels of the simulation results are reasonably reproducible. Thus, the FVCOM simulation was capable of qualitatively reproducing the water level fluctuations induced by typhoon winds with low calculation error. The calculation error could be attributed to the estimation errors of the local wind owing to the coarse horizontal resolution of the GPV-MSM, leading to reduced reproducibility of the gravity wave influencing the water level fluctuations. A numerical experiment with the case of no wind correction (using only $W_{M S M}$ ) was also conducted (Fig. 9a), yielding a clearly smaller peak at N3 and trough at S2. The case with no consideration of the air pressure on the lake surface shows little difference compared to the control run (not shown). These results suggested that the observed marked peaks at N3 and trough at S2 were generated by the gale-induced torrent attributed to the wind setup.

\subsection{Simulated results \\ 4.3.1 Gale-induced torrent}

Figure 10 shows three snapshots of the simulated water level distribution (color shading) and surface flow field (vectors) in the southern basin during the typhoon approach, indicating the generation of a gale-induced torrent. The northward torrent induced by the southsoutheast wind exceeded $1 \mathrm{~m} / \mathrm{s}$ in the northern area during 15:00-16:00 JST but was greater than the flow speed in the southern area. The water level was reduced by approximately $1.2 \mathrm{~m}$ due to the massive water transport associated with the northward torrent; consequently, the water level in the southern area was significantly lower than that in the northern area. On the other hand, after the south winds of the typhoon diminished (Fig. 11), the water level recovered to approximately $0 \mathrm{~m}$ during 17 : 00-19:00 JST. The temporal variation in the surface currents indicates that the southward backwash currents returned from the northern basin, and their speed exceeded $1 \mathrm{~m} / \mathrm{s}$ in the northern area; moreover, the speed of these currents in the northern area was greater than that in the southern area at 18:00 JST, when southward water transport was dominant. 


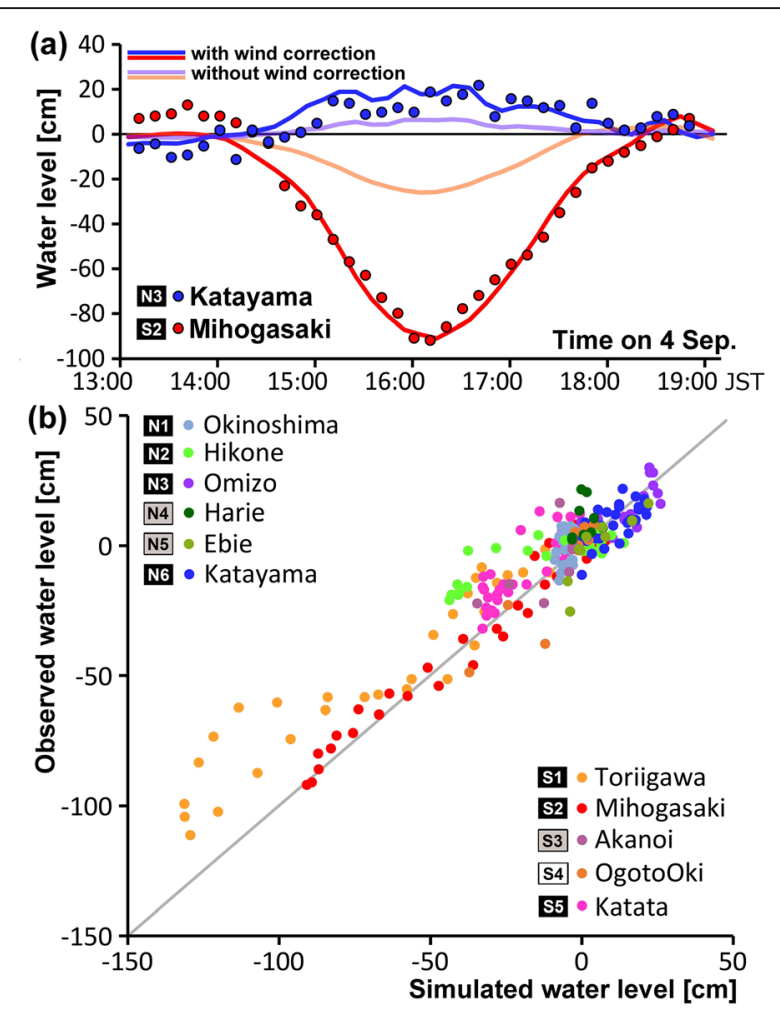

Fig. 9 a Temporal variation reflected in snapshots taken every ten minutes of the observed (colored dots) and simulated (colored lines) water levels in the cases with/without wind correction at the

Mihogasaki (red) and Katayama (blue) gauge stations corresponding to S2 and N2, respectively, as shown in Fig. 1. b Scatter plots showing the observed and simulated water levels during the period of 14:00-19:00 JST on 4 September. The colors of the dots indicate the eleven gauge stations (N1-N6, S1-S5), as shown in Fig. 1

Figure 12 shows maps of the maximum speeds and vectors of the surface and bottom currents. The horizontal pattern of the maximum current speed at the surface indicates that the northward current was dominant during the typhoon period. The maximum speed of the northern area was greater than that of the southern area and was particularly dominant but localized in the narrow strait around the Biwako-ohashi Bridge. The pattern of the maximum speed of the bottom current shows that the southward current was dominant in the direction opposite to that of the surface flow pattern. The dominant maximum bottom speed was also limited in the most northern area near the Biwako-ohashi Bridge.

Figure 13 shows the time series of the area-averaged water level (black solid line) in the southern basin (south of $35^{\circ} 7.8^{\prime} \mathrm{N}$ ); a prominent negative peak of the water level is visible at 16:10. The area-averaged flow speed at the surface shows two prevalent peaks of 0.83 and 0.51 $\mathrm{m} / \mathrm{s}$ at 15:10 and 17:20 JST, respectively; these apparent fluctuations suggest the to-and-fro transport of a large volume of $3.64 \times 10^{10} \mathrm{~m}^{3}$ (= the water level difference of
$0.71 \mathrm{~m} \times$ water area of the southern basin of $51.6 \mathrm{~km}^{3}$ ) between the southern and northern basins. Three peaks in the bottom speed were visible at 14:00, 15:20, and 16: 40 JST during the typhoon approach period (12:00-18: $00 \mathrm{JST})$; the maximum peak $(0.25 \mathrm{~m} / \mathrm{s})$ of the bottom flow was reached first, and its magnitude was approximately one-third that of the maximum peak of the surface flow. The temporal variation in the surface flow speed was similar to that of the depth- and areaaveraged flow speed in the southern basin (blue solid line), suggesting that the surface velocity field represented the flow dynamics in the southern basin. In contrast, the temporal variation after 20:00 indicates that small fluctuations occurred after the typhoon departed from the area.

\subsubsection{Erosion}

Figure 14 shows the maps used to evaluate the shear stress and erosion induced by the torrent at the bed. The map of the critical shear stress (Fig. 14a) derived by Eq. (3) shows the highest values in the northeastern area around the coast of the Karasuma Peninsula and in the southern area near the Ohmi-ohashi Bridge. These areas have a relatively low water content of less than $40 \%$ (Fig. 5 ); in particular, the area near the Ohmi-ohashi Bridge has an even lower water content of less than $20 \%$. Figure $14 \mathrm{~b}$ shows a map of the time-averaged bed shear stress during the period of 2-5 September obtained by Eq. (2); this map indicates high stress $\left(>0.5 \mathrm{~N} / \mathrm{m}^{2}\right)$ in the northern area, particularly in the strait area near the Biwakoohashi Bridge. These areas presented a greater bed stress than the areas exhibiting the dominant speed of the bottom flow (Fig. 12). Moreover, the values in the southern area were substantially smaller, ranging from 0 to $0.4 \mathrm{~N} /$ $\mathrm{m}^{2}$, except for the higher values at the head of the southern outlet flowing into the Seta River.

Based on the results of the critical and bed shear stresses (Fig. 14a and b), we derived a map of the timeaveraged nondimensional bed shear stress $\bar{R}_{\tau}$ (Fig. 14c) during the period of 2-5 September on the basis of Eq. (1). The $\bar{R}_{\tau}$ value was nearly zero and displayed a similar pattern to that of the bed shear stress (Fig. 14b), with a larger $\bar{R}_{\tau}$ in the northern area, particularly in the strait area. Hence, the bed shear stress associated with substantial erosion is expected to be small.

As a result of the nondimensional bed shear stress distribution, we derived a map of the total or timeintegrated erosion $E_{T}$ defined by Eq. (5) during the period of 2-6 September (Fig. 14d). This map indicates that the value of the erosion was nearly zero, except for the higher erosion $(>5 \mathrm{~cm})$ in the northernmost strait area. This suggests that most erosion was limited to the northernmost strait area according to the distribution 


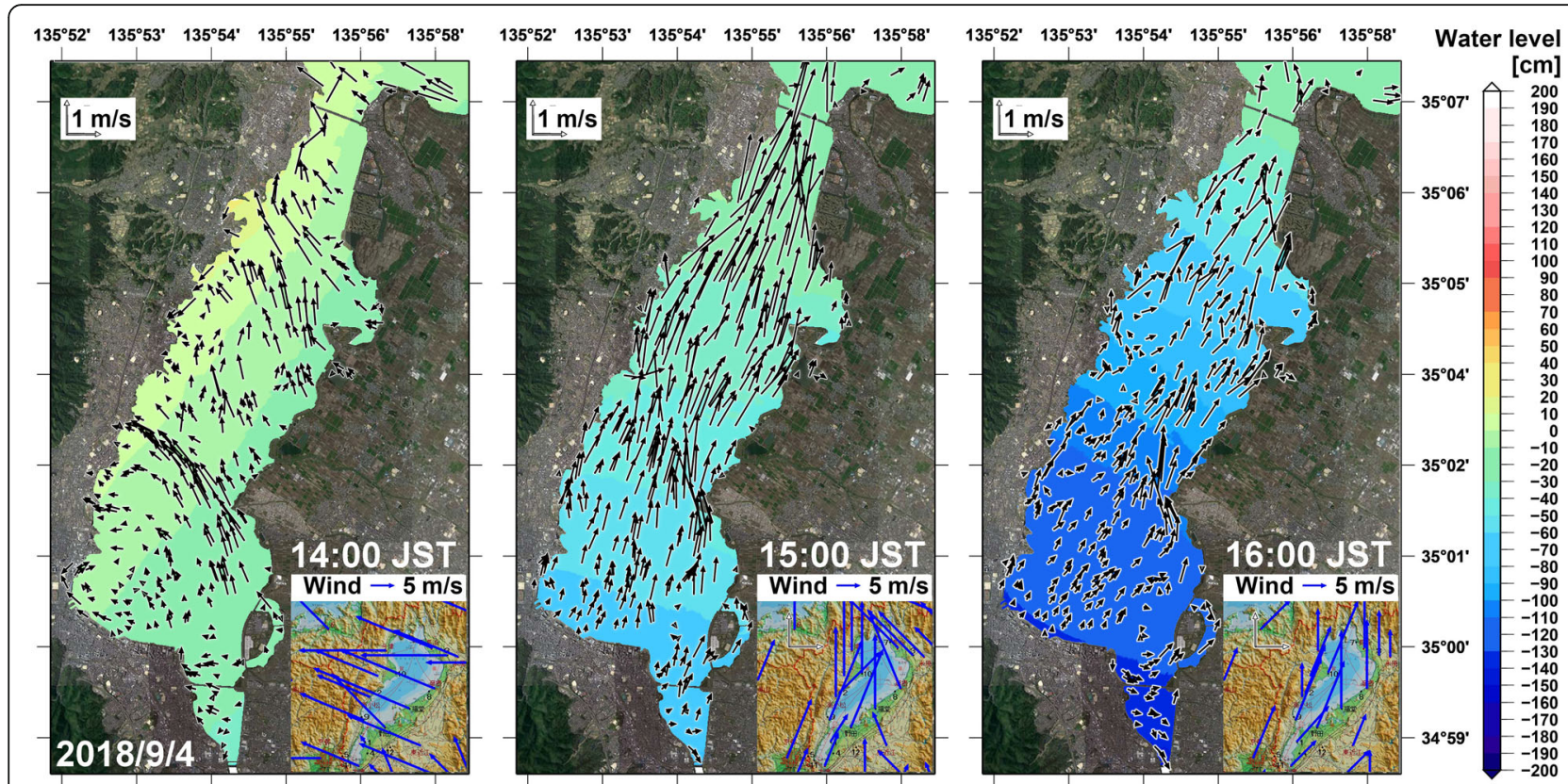

Fig. 10 Snapshots of maps of the simulated water level (color) and surface velocity field (vector) during the period in which Typhoon 21 approached Lake Biwa (14:00-16:00 JST) on 4 September 2018. The inset panels on the bottom right display the observed wind velocities (blue vectors) around Lake Biwa at each time; these data were provided by BiwakoDAS (https://koayu.eri.co.jp/Biwadas_Summary/)

pattern of $\bar{R}_{\tau}$ (Fig. 14c); this distribution is similar to the area with a high bed shear stress (Fig. 14b). Consequently, the magnitude of the bottom flow speed determined the magnitude of the nondimensional bed shear stress related to erosion.

\subsubsection{Fluid force}

We estimated the distribution of the fluid force $F_{F}$ using the flow velocity based on Eq. (13) and created maps of the maximum $F_{F}$ and time-averaged magnitude of the fluid force $\bar{F}_{F}$ during the period of 2-6 September

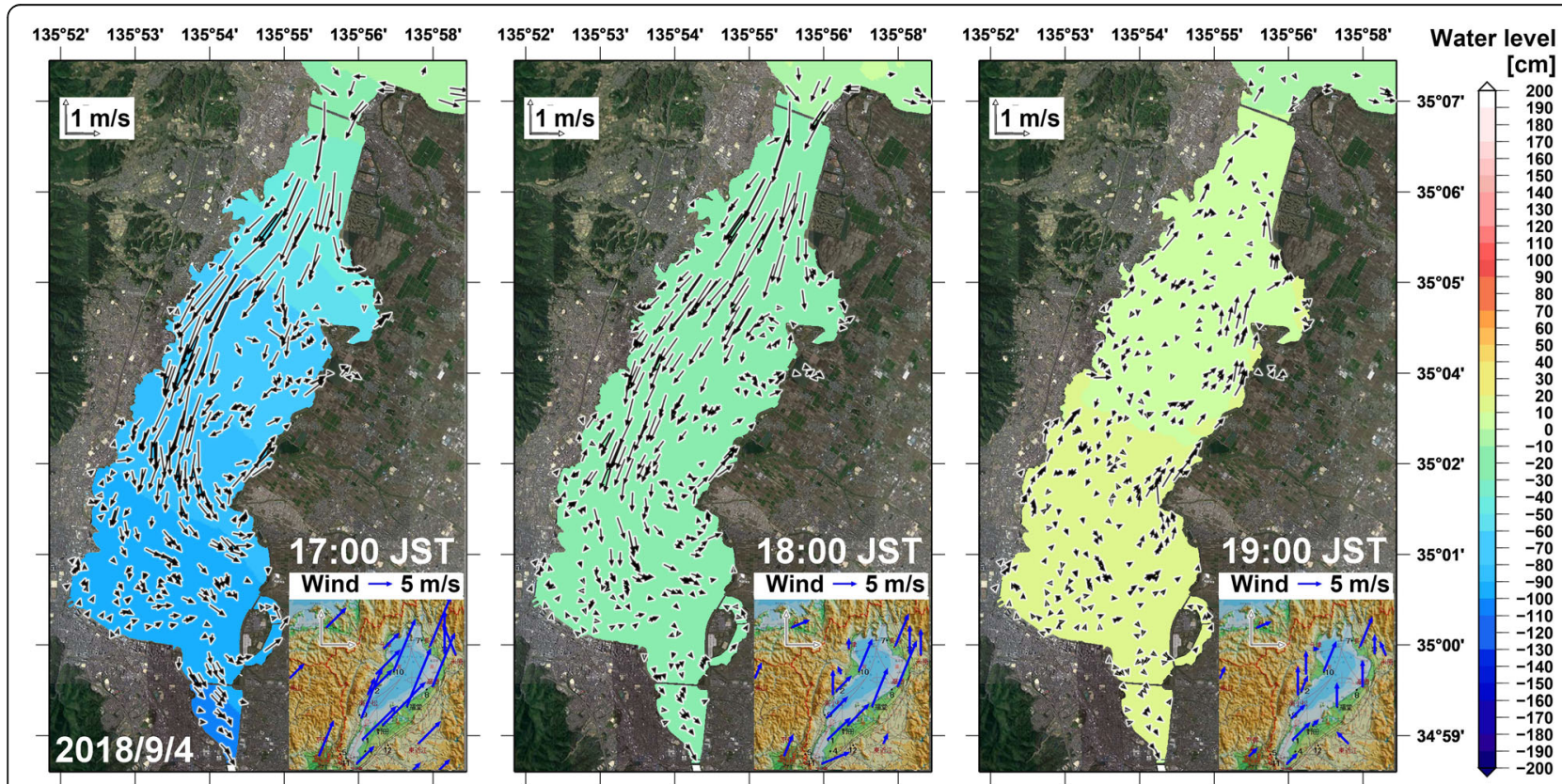

Fig. 11 The same data as in Fig. 10 but for the period when Typhoon 21 departed Lake Biwa (17:00-19:00 JST) 

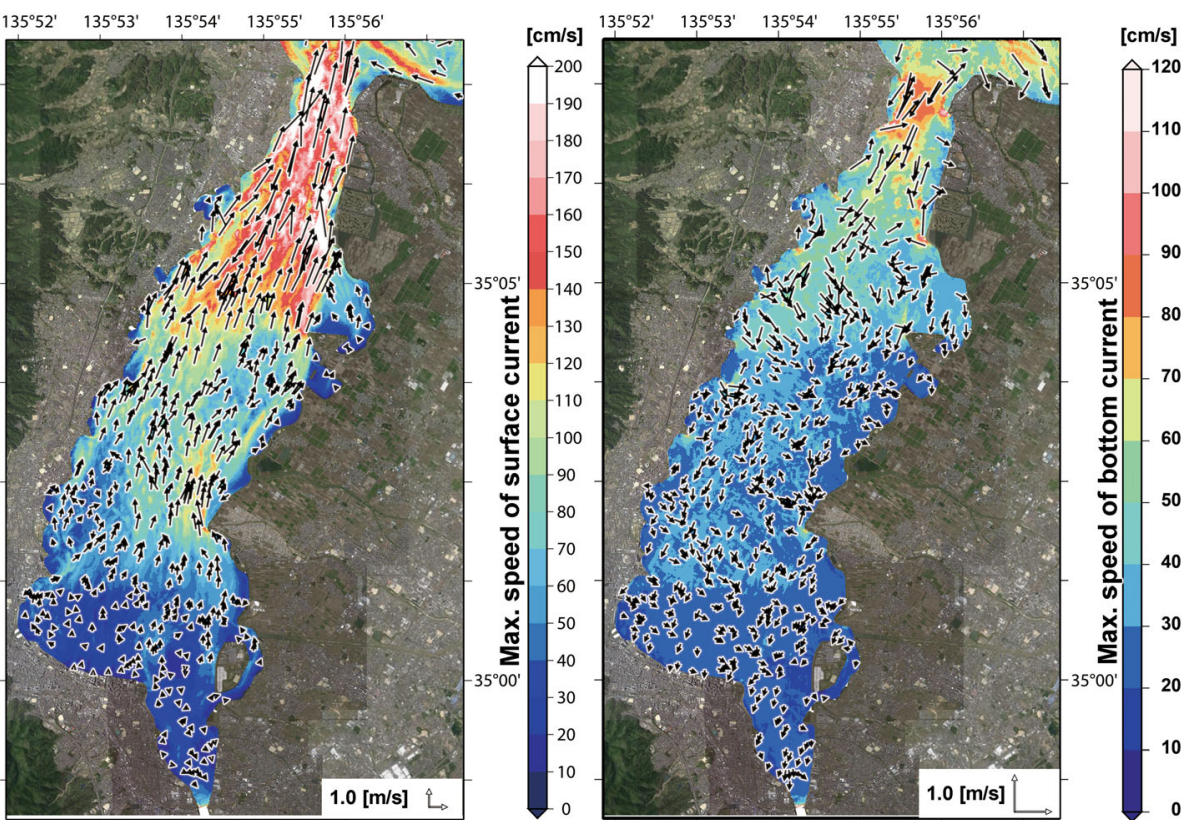

Fig. 12 Maps of the maximum velocity fields (vectors) and speeds (colors) for the surface (left) and bottom (right) currents simulated by the FVCOM during the period of 14:00-19:00 JST on 4 September 2018

(Fig. 15). The spatial pattern of the time-averaged $\bar{F}_{F}$ was similar to that of the maximum $F_{F}$; both patterns presented larger values in the north-central area, in the western coastal area, and in the estuarine area of the old Kusatsu River. These patterns mirrored the spatial pattern of the decrease in height of submerged macrophytes (Fig. $2 \mathrm{c}$ ), suggesting that the fluid force induced by the torrent could have uprooted the submerged macrophytes with the greatest heights and washed them out.

Figure 16 shows the time series of the area-averaged magnitude of the fluid force $\widehat{F_{F}}$ and the nondimensional bed shear stress $\widehat{R_{\tau}}$ in the southern basin. The temporal variation in $\widehat{F_{F}}$ was also predominant during the typhoon approach period and showed three peaks,

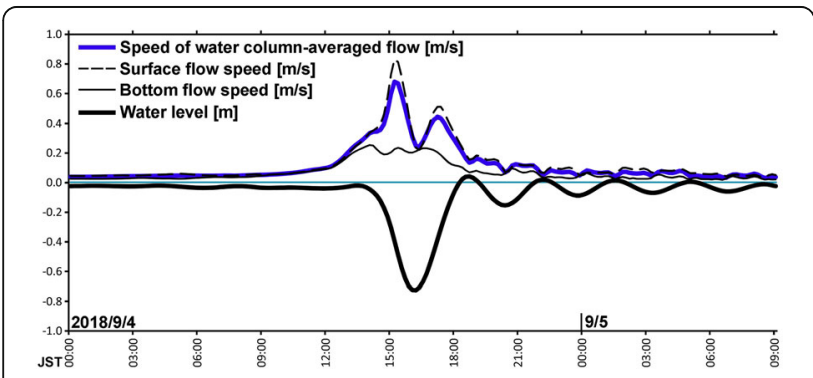

Fig. 13 Simulated time series of the water level (solid black line), the depth-averaged flow (solid blue line), the surface flow (dashed line), and the bottom flow speed (fine line) averaged over the area of the southern basin during the period from 0:00 JST on 4 September to 9:00 JST on 5 September although the first peak was small. The variation in $\widehat{F_{F}}$ was closer to that in the surface flow than to that in the bottom flow and remained large after the typhoon approach (Fig. 13). The temporal variation in $\widehat{R}_{\tau}$ exhibited three peaks during the typhoon approach period; these peaks corresponded to those of the bottom flow speed (Fig. 13), illustrating that the magnitude of $\widehat{R}_{\tau}$ was dominated by the magnitude of the bottom flow speed. Subsequently, the magnitude of $\widehat{R}_{\tau}$ rapidly diminished after the third peak and decreased to nearly zero after 18:00 JST.

Figure 17 shows the relationship between the timeaveraged fluid force $\bar{F}_{F}$ (Fig. 15) and the observed change in the water plant height $\left(\Delta h_{v}\right)$ using the values at each model grid (Fig. 6). Each averaged value was calculated by the data sorted with a bin of $\Delta h_{\nu}=0.1 \mathrm{~m}$. A close linear relationship is visible within the range of $\left(\Delta h_{v}\right)$ from - 1.3 to - $0.4 \mathrm{~m}$, corresponding to the area of the marked decrease in height (Fig. 6). The regression line $\left(\log _{10}\left(\bar{F}_{F}\right)=-0.81\right.$ $\left.\times \Delta h_{v}-4.23\right)$ was derived with a high correlation $\left(\mathrm{R}^{2}=\right.$ $0.94)$, indicating that the reliable range of $\Delta h_{v}$ can be estimated from the calculated fluid force. When the decreased height is the minimum limit $\left(\Delta h_{v}=-0.4\right.$ $\mathrm{m}), \log _{10}\left(\bar{F}_{F}\right)$ took the value -3.91 calculated from the regression and the averaged fluid force $\left(1.24 \times 10^{-4}\right.$ $\mathrm{N})$. This suggests the limitations of the fluid force model and indicates that within the range $\log _{10}\left(\bar{F}_{F}\right)$ $<-3.91$, it might be difficult to estimate the decreased height $\left(\Delta h_{v}\right)$ from the simulated $F_{F}$. The 

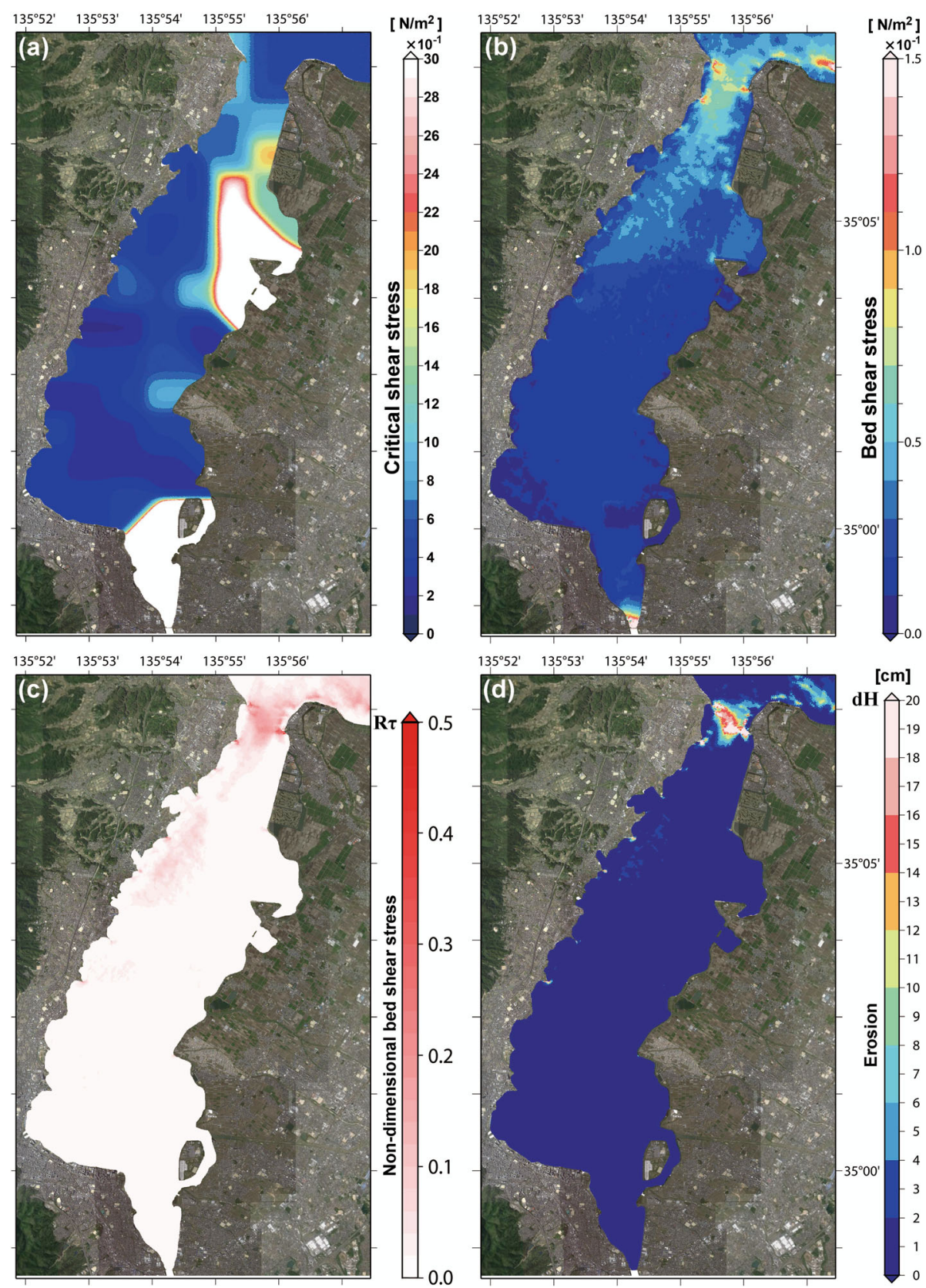

$135^{\circ} 52^{\prime} \quad 135^{\circ} 53^{\prime} \quad 135^{\circ} 54^{\prime} \quad 135^{\circ} 55^{\prime} \quad 135^{\circ} 56^{\prime}$

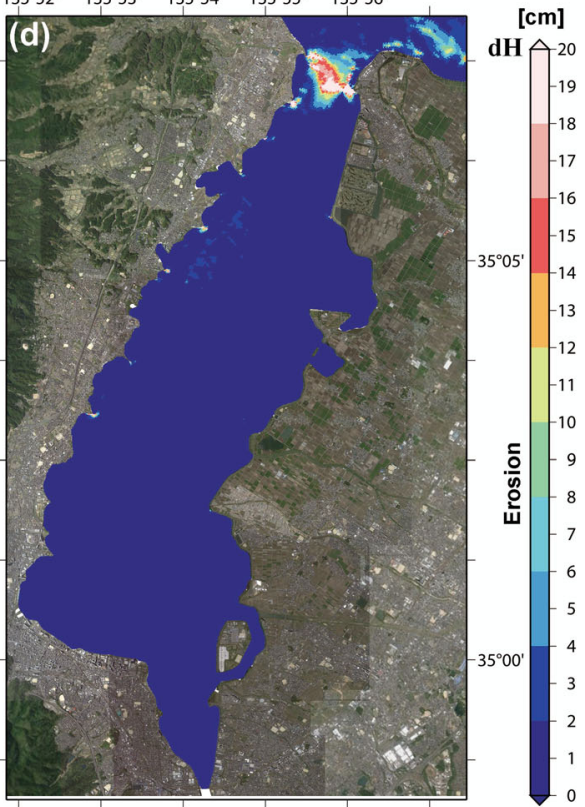

Fig. 14 Maps of $\mathbf{a}$ the critical shear stress, $\mathbf{b}$ the time-averaged bed shear stress, $\mathbf{c}$ the time-averaged nondimensional bed shear stress, and $\mathbf{d}$ the time-integrated erosion from the lakebed during the period 0:00-23:50 JST on 4 September

maximum fluid force $\left(3.62 \times 10^{-2} \mathrm{~N}\right)$ when $\Delta h_{v}=-0.4 \mathrm{~m}$ can also be derived, which corresponds to flow speeds of $0.8 \pm 0.5$ (standard deviation) $\mathrm{m} / \mathrm{s}$. This speed can be the critical value to induce the fluid force acting on the uprooting of the submerged macrophytes.

\section{Discussion}

This paper highlights that the fluid force (rather than the erosion) driven by a gale-induced torrent during the approach of a typhoon at Lake Biwa uprooted the submerged macrophytes therein, leading to the massive outflow of those macrophytes from a large area of the southern basin of Lake Biwa. These results demonstrate that a previously proposed theoretical framework (e.g., Luhar and Nepf 2011) and analytical model (Hayashi and Konno 2007) are applicable even to the high flow speed range of $1 \mathrm{~m} / \mathrm{s}$ or greater for calculating the fluid force acting on submerged macrophytes. Our approach can contribute to assessing the damage to and erosion risk of aquatic populations in various lakes (Chiu et al. 


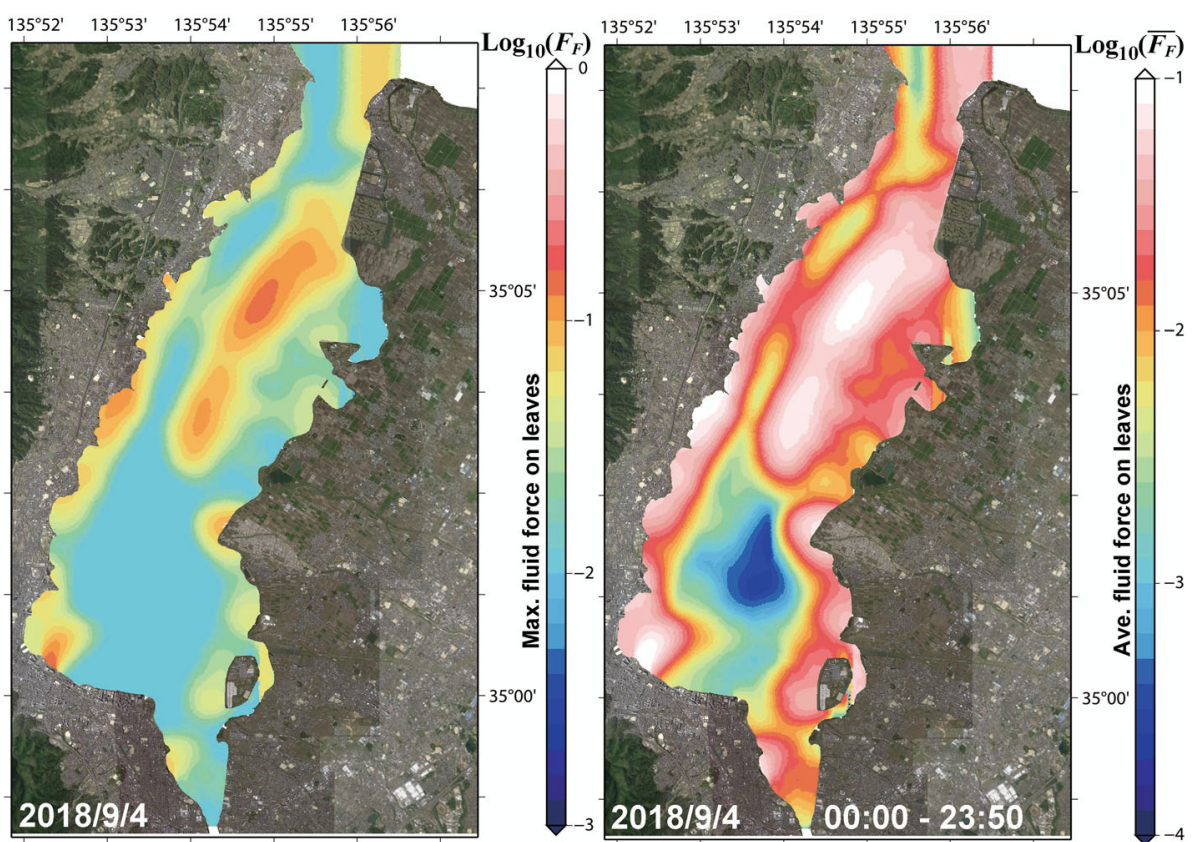

Fig. 15 Maps of the maximum (left) and time-averaged (right) fluid forces acting on the submerged macrophytes during the period of 0:0023:50 JST on 4 September

2017), particularly in lakes with aquatic macrophyte habitats, during storm strikes worldwide (Short et al. 2016). In particular, based on an evaluation considering violent, high-intensity typhoon strikes projected under climate change scenarios (Mei and Xie 2016), we can estimate the frequency at which submerged macrophytes will experience massive losses in the future. These findings are expected to lead to an understanding of lake ecosystems and the creation of adaptation strategies to cope with projected climate change with respect to short-term events attributed to typhoon strikes (Jeppesen et al. 2017).

The massive loss of submerged macrophytes could decrease the fish stock. In fact, the bluegill (Lepomis macrochirus) in Lake Biwa, the population of which is

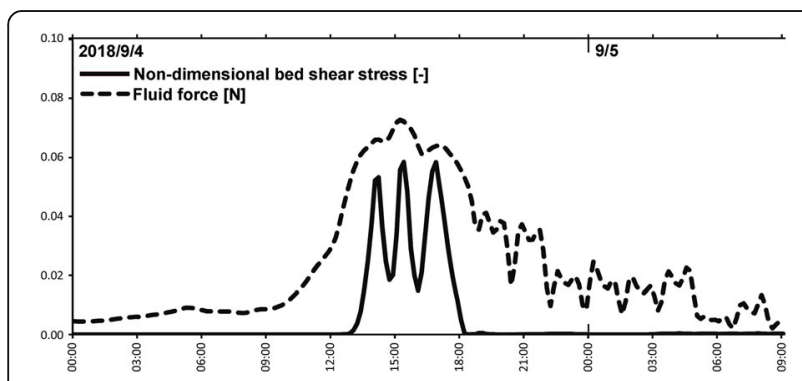

Fig. 16 Simulated time series of the nondimensional bed shear stress (solid line) and fluid force acting on the submerged macrophytes (broken line) averaged over the area of the southern basin during the period from 0:00 on 4 September to 9:00 JST on 5 September decreasing interannually with an overall rapidly decreasing trend, reached a minimum level in 2019, as shown by the fish catch data archived on the Shiga Prefecture website (https://www.pref.shiga.lg.jp/ippan/ kankyoshizen/biwako/307015.html). This may be attributable to the short-term, typhoon-induced, drastic decrease in the submerged macrophyte bed since submerged macrophytes can provide a habitat for invertebrates and act as feeding sites and refugia for bluegill (Miller et al. 2018). There were similar events due to the typhoon approach on 16 September 1961 (Typhoon 18, Nancy) but no evidence for the short-term, typhooninduced, drastic decrease in the submerged macrophytes because the submerged macrophytes were luxuriant after 1997. Cross and McInerny (2005) reported that these changes in submerged plant cover and its detritus substrates can primarily explain the spatial variation in bluegill abundance. According to Schriver et al. (1995), changes in the abundance of submerged macrophytes can impact fish-zooplankton-phytoplankton interactions in shallow eutrophic lakes.

The reproducibility of our simulation results depends on the accuracy of the wind and current velocity data, which is a limitation of our approach. We evaluated the accuracy of the simulated water level compared with the observed water level (RMSE: $0.12 \mathrm{~m}$ ); this value falls within 9\% of the water level amplitude (approximately $1.4 \mathrm{~m}$ ) of both the observed and the simulated fluctuations, suggesting sufficient reproducibility in analyses of the fluctuations generated by a typhoon gale. Note that 


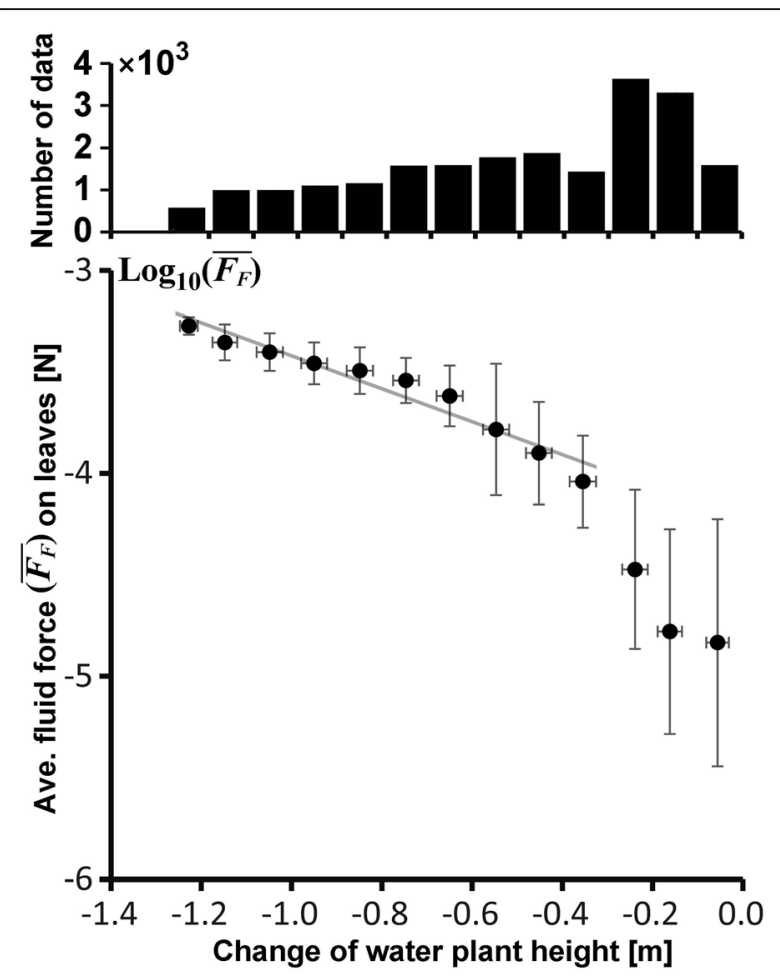

Fig. 17 The relationship between the time-averaged fluid force (Fig. 15) and height changes of the submerged macrophytes (Fig. 6). The upper panel shows the number of sample data counted in all grids of the southern basin with a bin of $0.1 \mathrm{~m}$ for the height changes of the submerged macrophytes. The lower panel shows the plots of the averaged values for the fluid forces and height changes (black dots) with the standard deviation (bars) using the sample data

the accuracy of the wind estimation at the lake surface can substantially contribute to the reproducibility of our flow simulation and depends on the observational error of the wind observations. Both the wind speed and the wind direction can significantly affect the fetch in the southern basin and the intensity of the gale-induced torrent. The accuracy of our simulation could decline without the validation of the GPV-MSM-predicted wind based on observational data of the lake surface wind. The fluid force model used in the simulation is simple because the fluid force is determined by two variables (input data) for the simulated current speed driven mainly by the lake surface wind and the observed plant height. We verified the validity of the simulated results based on observational water level data, suggesting that a limitation of our model is that the accuracy of the simulated current velocity is unknown. The current velocity must be observed in the areas with submerged macrophyte beds for a comparison with the simulated velocity to improve the accuracy of the simulated speed. The fluid force model adopted in this study is simple and conventional, but our results suggested that the model can be used to estimate the horizontal distribution of aquatic plants uprooted and washed out by gale-induced torrents during extreme events, such as when typhoons approach. This approach can be practical for evaluating changes in lake environments attributed to the massive outflow of submerged macrophytes under various climate change scenarios, although the fluid force and flow speed should be verified by observational data in future studies.

Wind-induced waves may also contribute to waveinduced currents, generating fluid forces and bed shear stress generating erosion, resulting in macrophyte uprooting. We evaluated the representative wave height $H_{w}(=0.5 \mathrm{~m})$ and period $T_{w}(=2.2 \mathrm{~s})$ during the typhoon approach period of 14:00-19:00 JST on 4 September based on the simple Sverdrup-Munk-Bretschneider (SMB) method (Bretschneider 1970) using the observed wind speeds $(14.5-19.6 \mathrm{~m} / \mathrm{s})$ and supposing typical fetches $(3-4 \mathrm{~km})$. Considering the area-mean depth $D(=$ $4 \mathrm{~m}$ ) of the southern basin and wavelength $L_{w}=g T_{w}{ }^{2} /$ $(2 \pi)(=7.5 \mathrm{~m})$, we obtained the scale criterion $D / L_{w}>1 / 2$, indicating that the wind wave induced by the typhoon gale was a deep-water wave. The orbital of the deepwater wave is exponentially decreased, and its halfexcursion near the bottom requires approximately $e^{-D} H_{w}$ as well as the orbital velocity. As a result, we derived the typical wave-induced current $U_{b}=2 \pi e^{-D} H_{w} /$ $T_{w}(=0.03 \mathrm{~m} / \mathrm{s})$ near the bottom based on a similar calculation (Dufois et al. 2008). The current speed of $U_{b}$ was less than that of the torrent-induced current, as shown in Fig. 12, suggesting that the effect of wind waves is negligible. Therefore, wind-induced waves and wave-induced currents can secondarily contribute to erosion and fluid forces.

The bed flow may scour the sediments around the submerged macrophytes, although the simulated bed flow was low in the results of this study. The scouring depth $S$ is primarily determined by the flow speed and the diameter (Sumer and Fredsøe 2001). Classically, the scouring depth is empirically determined as $S / D=1.3$, where $D$ is the diameter of the cylinder. A more accurate $S$ within the available range $S / D<2.7$ can be estimated from the speed of the bed flow if it is known (e.g., Qi and Gao 2014). Assuming that D is the typical stem width of submerged macrophytes (b $=0.01 \mathrm{~m})$ in this study, within $S / D<2.7, S$ is calculated to be a maximum $2.7 \mathrm{~cm}$ smaller than the typical root depth of submerged macrophytes $(>6 \mathrm{~cm})$. This result suggests that uprooting induced by this scouring effect was negligible.

This study illustrates that a high-resolution grid of several tens of meters is highly suitable to reproduce the current velocity induced by a typhoon strike. Our model is composed of grids with a high horizontal resolution (10-60 m), as shown in Fig. 6, which corresponds to the 
longitudinal resolution of the echosounder observation system used to measure the vegetation height of the submerged macrophytes (Fig. 1d). This resolution can contribute to a direct comparison between the observed heights of the submerged macrophytes and estimated fluid force and erosion acting on the submerged macrophytes. A reasonable calculation of the fluid force and erosion requires a high horizontal resolution using a realistically simulated water level and flow in the southern basin. In comparison, a model using a coarser spatial resolution than that of our model experienced difficulty simulating the highspeed currents generated by an atmospheric disturbance and was therefore insufficient (Nakada et al. 2014). To date, the grid resolutions of previously proposed models have been greater than $0.5 \mathrm{~km}$ because the main purpose of those models was to reproduce the lake circulation associated with the seasonal thermocline and the interannual variations in the lake water temperature (e.g., Akitomo et al. 2009; Koue et al. 2018). We first employed a flow model with a regular $0.5 \mathrm{~km}$ grid to simulate the gale-induced current, but the reproducibility of the water level was insufficient for our analyses (not shown).

The massive outflow of submerged macrophytes induced by storm strikes can drastically change the lake ecosystem and environment and should be investigated with respect to climate change scenarios (Jeppesen et al. 2017). A southwest wind greater than 20 $\mathrm{m} / \mathrm{s}$ blew during the study period for longer than $3 \mathrm{~h}$ (Fig. 8), inducing a northward torrent and volumetric transport from the southern basin to the northern basin (Figs. 10 and 11). We confirmed that the concentration of chlorophyll-a in the southern basin after the typhoon approach nearly doubled relative to the concentration during the pretyphoon period between 1 and 3 September (Fig. 3). This suggests that shortterm blooms of toxic cyanobacteria harmful algal bloom (HAB) species might occur over a large area of the southern basin once the turbidity has declined, as indicated by Havens et al. (2016a). Typhoons will be more intense and violent under the future projected climate of East Asia (Mei and Xie 2016), which could increase the possibility of events that generate a variety of consequences, such as massive losses and rapid increases in HABs. Similar problems can be shared among the many global lakes with submerged macrophyte vegetation. We suggest the analysis of typhoon strikes focusing on various lakes at a worldwide scale based on regional climate change scenarios to enable the exploration of possible drastic changes in lake environments triggered by the massive loss of submerged macrophytes.

\section{Conclusions}

This study examined the massive loss of submerged macrophytes induced by a super typhoon and investigated the physical processes responsible for the outflow of vegetation using a high-resolution flow model. The simulated results demonstrated that the fluid force driven by a gale-induced torrent uprooted the submerged macrophytes during the typhoon approach; this fluid force (rather than erosion) was the mechanism responsible for the removal of macrophytes. As a result, these processes induced the massive loss of submerged macrophytes over the large area of the southern basin of Lake Biwa.

The proposed high-resolution flow model will be essential for evaluating the short-term, massive losses induced by typhoon strikes, although the reproducibility of the simulation depends on the accuracy of the wind data. The massive outflow of submerged macrophytes induced by storm strikes can drastically change the ecosystem and environment of a lake, leading to a possible reduction in the fish stock and an increase in primary production. Our simulation successfully reproduced the abnormal fluctuation of the water level generated by the typhoon gale. The model accuracy of our flow simulation using high-resolution grids was acceptable for the fluid force analysis and did not affect our conclusion. We hope that such drastic changes attributed to the massive outflow of submerged macrophytes will be investigated based on climate change scenarios.

\section{Abbreviations}

FVCOM: Finite-volume community ocean model; LBERI: Lake Biwa

Environmental Research Institute; GPV-MSM: Grid Point Value datasets of the Meso-Scale Model; LBM: Lake Biwa Museum; CSV: Comma-separated values; JMA: Japan Meteorological Agency; MLIT: Ministry of Land, Infrastructure, Transport and Tourism; JWA: Japan Water Agency; JST: Japan Standard Time; HAB: Harmful algal bloom

\section{Acknowledgements}

This work was supported by a grant from the Collaborative Research Fund from Shiga Prefecture "Studies on conservation and ecosystem management of Lake Biwa" under the Japanese Grant for Regional Revitalization. We thank Dr. C. Jiao, LBERI, for providing the bathymetry grid data of Lake Biwa. We deeply appreciate Mr. K. Hatano, JWA, for providing the observational meteorological data, such as wind and air pressure. In this research, we used the supercomputer of ACCMS, Kyoto University. We thank the Research Institute for Sustainable Humanosphere, Kyoto University, for providing the input datasets of GPV-MSM. We deeply appreciate two anonymous reviewers and the editor for their fruitful comments.

\section{Authors' contributions}

SN mainly contributed to the writing of the paper, modeling, simulation, and data analysis. $\mathrm{HH}$ contributed to the observation of the plant height of macrophytes by an echosounder. MI contributed to the in situ data collection and analysis of the water level time series. KM contributed to the in situ data collection of the water level time series at various sites. NT mainly contributed to the study design of this paper and many discussions. The authors read and approved the final manuscript. 


\section{Funding}

This work was supported by the Collaborative Research Fund from Shiga Prefecture "Studies on conservation and ecosystem management of Lake Biwa" under the Japanese Grant for Regional Revitalization.

\section{Availability of data and materials}

Please contact author for data requests.

\section{Declarations}

\section{Competing interests}

The authors declare that they have no competing interests.

\section{Author details}

${ }^{1}$ National Institute for Environmental Studies, 16-2 Onogawa, Tsukuba, Ibaraki 305-8506, Japan. Lake Biwa Museum, 1091 Oroshimo-cho, Kusatsu, Shiga 525-0001, Japan

Received: 22 December 2020 Accepted: 4 July 2021

Published online: 16 August 2021

\section{References}

Akitomo K, Tanaka K, Kumagai M (2009) Annual cycle of circulations in Lake Biwa part 2: mechanisms. Limnology 10(2):119-129. https://doi.org/10.1007/s102 01-009-0268-6

Bretschneider CL (1970) Forecasting relations for wave generation. Look Lab, Hawaii 1(3):31-34

Chen C, Liu H, Beardsley RC (2003) An unstructured grid, finite-volume, three dimensional, primitive equations ocean model: application to coastal ocean and estuaries. J Atmos Ocean Technol 20(1):159-186. https://doi.org/10.11 75/1520-0426(2003)020<0159:AUGFVT>2.0.CO;2

Chiu Y-T, Bain A, Deng S-L, Ho Y-C, Chen W-H, Tzeng H-Y (2017) Effects of climate change on a mutualistic coastal species: Recovery from typhoon damages and risks of population erosion. PLoS One 12(10):e0186763. https:// doi.org/10.1371/journal.pone.0186763

Cross TK, Mclnerny MC (2005) Spatial habitat dynamics affecting bluegill abundance in Minnesota bass-panfish Lakes. N Am J Fish Manag 25(3):10511066. https://doi.org/10.1577/M04-072.1

Dhote S, Dixit S (2009) Water quality improvement through macrophytes-a review. Environ Monit Assess 152(1-4):149-153. https://doi.org/10.1007/s1 0661-008-0303-9

Dufois F, Garreau P, Le Hir P, Forget P (2008) Wave-and current-induced bottom shear stress distribution in the Gulf of Lions. Cont Shelf Res 28(15):1920-1934. https://doi.org/10.1016/j.csr.2008.03.028

Ellison JC (1998) Impacts of sediment burial on mangroves. Mar Pollut Bull 37(812):420-426

Haga $H$ (2006) Confirmation of surface area of the southern basin of Lake Biwa, Japan. Jpn J Limnol 67(2):123-126. https://doi.org/10.3739/rikusui.67.123 [in Japanese]

Haga H, Ishikawa K (2016) Spatial distribution of submerged macrophytes in the southern Lake Biwa basin in the summer of 2014, in comparison with those in 2002, 2007 and 2012. Jpn J Limnol 77(1):55-64. https://doi.org/10.3739/ rikusui.77.55

Haga H, Ohtsuka T, Matsuda M, Ashiya M (2006) Spatial distributions of biomass and species composition in submerged macrophytes in the southern basin of Lake Biwa in summer of 2002. Jpn J Limnol 67(2):69-79. https://doi.org/1 0.3739/rikusui.67.69 [in Japanese]

Havens K, Paerl H, Phlips E, Zhu M, Beaver J, Srifa A (2016a) Extreme weather events and climate variability provide a lens to how shallow lakes may respond to climate change. Water 8(229):1-18. https://doi.org/10.3390/ w8060229

Havens KE, Fulton RS III, Beaver JR, Samples EE, Colee J (2016b) Effects of climate variability on cladoceran zooplankton and cyanobacteria in a shallow subtropical lake. J Plankton Res 38(3):418-430. https://doi.org/10.1093/plankt/ fbw009

Hayashi K, Konno M (2007) Fluid forces and hydraulic resistance by plants deforming and oscillatig in river flow. Proc Hydraulic Eng 51:1231-1236. https://doi.org/10.2208/prohe.51.1231 [in Japanese]

Howes NC, FitzGerald DM, Hughes ZJ, Georgiou IY, Kulp MA, Miner MD, Smith JM, Barras JA (2010) Hurricane-induced failure of low salinity wetlands. Proc Natl Acad Sci U S A 107(32):14014-14019
IPCC (2007) Summary for policymakers. In: Solomon S, Qin D, Manning M, Chen Z, Marquis M, Averyt KB, Tignor M, Miller HL (eds) Climate Change 2007; The physical science basis. Contribution of Working Group I to the Fourth Assessment Report of the Intergovernmental Panel on Climate Change. New York: Cambridge University Press

Jeppesen E, Søndergaard M, Liu Z (2017) Lake restoration and management in a climate change perspective: an introduction. Water 9(2):122. https://doi.org/1 0.3390/w9020122

Ji G, Havens KE, Beaver JR, East TL (2018) Recovery of plankton from hurricane impacts in a large shallow lake. Freshw Biol 63:366-379. https://doi.org/1 $0.1111 /$ fwb.13075

Kawanabe H, Nishino M, Maehata M (2012) Lake Biwa: interactions between nature and people. Springer. https://doi.org/10.1007/978-94-007-1783-1

Kitazawa D, Kumagai M, Hasegawa N (2010) Effects of internal waves on dynamics of hypoxic waters in Lake Biwa. J Korean Soc Mar Environ Energy 13(1):30-42

Koue J, Shimadera H, Matsuo T, Kondo A (2018) Evaluation of thermal stratification and flow field reproduced by a three-dimensional hydrodynamic model in Lake Biwa, Japan. Water 10(47):1-20. https://doi. org/10.3390/w10010047

Luhar M, Nepf HM (2011) Flow-induced reconfiguration of buoyant and flexible aquatic vegetation. Limnol Oceanogr 56(6):2003-2017. https://doi.org/10.431 9/lo.2011.56.6.2003

McKinnon SL, Mitchell SF (1994) Eutrophication and black swan (Cygnus atratus Latham) populations: tests of two simple relationships. In: Aquatic birds in the trophic web of lakes. Springer, Dordrecht, pp 163-170. https://doi.org/1 0.1007/978-94-011-1128-7_16

Mei W, Xie S-P (2016) Intensification of landfalling typhoons over the northwest Pacific since the late 1970s. Nat Geosci 9(10):753-757. https://doi.org/10.103 8/NGEO2792

Miller JW, Kocovsky PM, Wiegmann D, Miner JG (2018) Fish community responses to submerged aquatic vegetation in Maumee Bay, Western Lake Erie. N Am J Fish Manag 38(3):623-629. https://doi.org/10.1002/nafm.10061

Nakada S, Hayashi M, Koshimura S (2018) Transportation of sediment and heavy metals resuspended by a giant tsunami based on coupled three-dimensional tsunami, ocean, and particle-tracking simulations. J Water Environ Technol 16(4):161-174. https://doi.org/10.2965/jwet.17-028

Nakada S, Hayashi M, Koshimura S, Taniguchi Y, Kobayashi E (2017) Salinization by Tsunami in a semi-enclosed bay: tsunami-ocean 3D simulation based on the great earthquake scenario along the Nankai Trough. J Adv Simulat Sci Eng 3(2):206-214

Nakada S, Hirose N, Senjyu T, Fukudome K, Tsuji T, Okei N (2014) Operational ocean prediction experiments for smart coastal fishing. Prog Oceanogr 121: 125-140. https://doi.org/10.1016/j.pocean.2013.10.008

Nakada S, Isoda Y (2000) Seasonal variation of the Tsushima Warm Current off Toyama Bay. Umi Sora 76:17-24 [in Japanese]

Nakano S, Ito N, Inoue H (1991) Critical yield and shear stresses for mud erosion under wave. Proc Coast Eng JSCE 38:461-465 [in Japanese]

Otsubo K, Muraoka K (1985) Physical properties and critical shear stress of cohesive bottom sediments. J Hydraulic Coastal Environ Eng 363(II-4):225234 [in Japanese]

Qi WG, Gao FP (2014) Physical modeling of local scour development around a large-diameter monopile in combined waves and current. Coast Eng 83:7281. https://doi.org/10.1016/j.coastaleng.2013.10.007

Sato Y, Komatsu E, Nagare H, Uehara H, Yuasa T, Okubo T, Okamoto T, Kim J (2011) Construction and validation of Lake Biwa basin simulation model with integration of three components of land, lake flow, and lake ecosystem. J Jpn Soc Water Environ 34(9):125-141. https://doi.org/10.2965/jswe.34.125

Scheffer M, van Nes EH (2007) Shallow lakes theory revisited: various alternative regimes driven by climate, nutrients, depth and lake size. Hydrobiologia 584(1):455-466. https://doi.org/10.1007/s10750-007-0616-7

Schriver P, Bøgestrand J, Jeppesen E, Søndergaard M (1995) Impact of submerged macrophytes on fish-zooplankton-phytoplankton interactions: large-scale enclosure experiments in a shallow eutrophic lake. Freshw Biol 33(2):255-270. https://doi.org/10.1111/j.1365-2427.1995.tb01166.x

Short FT, Kosten S, Morgan PA, Malone S, Moore GE (2016) Impacts of climate change on submerged and emergent wetland plants. Aquat Bot 135:3-17. https://doi.org/10.1016/j.aquabot.2016.06.006

Sood A, Uniyal PL, Prasanna R, Ahluwalia AS (2012) Phytoremediation potential of aquatic macrophyte, Azolla. AMBIO 41(2):122-137. https://doi.org/10.1007/ s13280-011-0159-z 
Sumer BM, Fredsøe J (2001) Scour around pile in combined waves and current. J Hydraul Eng 127(5):403-411. https://doi.org/10.1061/(ASCE)0733-9429(2001 )127:5(403)

Umita T, Kasuda T, Futawatari T, Awaya Y (1988) Study on erosional process of soft muds. J Hydraulic Coastal Environ Eng 398(II-9):33-42 [in Japanese]

Wang Q, Yu D, Li Z, Wang L (2008) The effect of typhoons on the diversity and distribution pattern of aquatic plants on Hainan Island, South China. Biotropica 40(6):692-699. https://doi.org/10.1111/j.1744-7429.2008.00430.x

Wang X, Wang W, Tong C (2016) A review on impact of typhoons and hurricanes on coastal wetland ecosystems. Acta Ecol Sin 36(1):23-29. https://doi.org/10.1 016/j.chnaes.2015.12.006

Weisner SEB, Strand JA, Sandsten H (1997) Mechanisms regulating abundance of submerged vegetation in shallow eutrophic lakes. Oecologia 109(4):592-599. https://doi.org/10.1007/s004420050121

Yanran D, Chenrong J, Wei L, Shenghua H, Zhenbin W (2012) Effects of the submerged macrophyte Ceratophyllum demersum L. on restoration of a eutrophic waterbody and its optimal coverage. Ecol Eng 40:113-116. https:// doi.org/10.1016/j.ecoleng.2011.12.023

\section{Publisher's Note}

Springer Nature remains neutral with regard to jurisdictional claims in published maps and institutional affiliations.

\section{Submit your manuscript to a SpringerOpen ${ }^{\circ}$ journal and benefit from:}

- Convenient online submission

- Rigorous peer review

- Open access: articles freely available online

- High visibility within the field

- Retaining the copyright to your article

Submit your next manuscript at $\boldsymbol{\nabla}$ springeropen.com 